\title{
Financial Development, Growth, and the Distribution of Income
}

\section{Jeremy Greenwood}

Federal Reserve Bank of Minneapolis and University of Western Ontario

\section{Boyan Jovanovic}

New York University

\begin{abstract}
A paradigm is presented in which both the extent of financial intermediation and the rate of economic growth are endogenously determined. Financial intermediation promotes growth because it allows a higher rate of return to be earned on capital, and growth in turn provides the means to implement costly financial structures. Thus financial intermediation and economic growth are inextricably linked in accord with the Goldsmith-McKinnon-Shaw view on economic development. The model also generates a development cycle reminiscent of the Kuznets hypothesis. In particular, in the transition from a primitive slow-growing economy to a developed fastgrowing one, a nation passes through a stage in which the distribution of wealth across the rich and poor widens.
\end{abstract}

\section{Introduction}

Two themes pervade the growth and development literature. The first is Kuznets's (1955) hypothesis on the relationship between economic growth and the distribution of income. On the basis of some-

This paper has benefited enormously from the unusually detailed criticism of Robert Townsend, Neil Wallace, and two anonymous referees; we are in their debt. Comments from Robert Barro, James Kahn, Patrick Kehoe, Ariel Pakes, and Kenneth Rogoff are also gratefully acknowledged. The views expressed herein are those of the authors and not necessarily those of the Federal Reserve Bank of Minneapolis or the Federal Reserve System. 
what slender evidence, Kuznets cautiously offered the proposition that during the course of an economy's lifetime, income inequality rises during the childhood stage of development, tapers off during the juvenile stage, and finally declines as adulthood is reached. While this hypothesis is far from being incontrovertible, other researchers have found evidence in support of it. For example, Lindert and Williamson (1985) suggest that "British experience since 1688 looks like an excellent advertisement for the Kuznets Curve, with income inequality rising across the Industrial Revolution, followed by a prolonged leveling in the last quarter of the nineteenth century" (p. 344). Using cross-country data, Paukert (1973) finds evidence that intracountry income inequality rises and then declines with economic development. Finally, intercountry inequality is examined by Summers, Kravis, and Heston (1984). They discover that income inequality fell sharply across industrialized countries from 1950 to 1980 , declined somewhat for middle-income ones, and rose slightly for low-income nations. ${ }^{1}$ Of related interest is their finding that between 1950 and 1980 , real per capita income grew at about half the rate for lowincome countries that it did for high- and middle-income nations.

The second major strand of thought prevalent in the growth and development literature, often associated with the work of Goldsmith (1969), McKinnon (1973), and Shaw (1973), stresses the connection between "a country's financial superstructure and its real infrastructure." Simply put by Goldsmith, the financial superstructure of an economy "accelerates economic growth and improves economic performance to the extent that it facilitates the migration of funds to the best user, i.e., to the place in the economic system where the funds will yield the highest social return" (p. 400). Further evidence, again not decisive, establishes a link between financial structure and economic development. For instance, Goldsmith presents data showing a welldefined upward secular drift in the ratio of financial institutions' assets to gross national product for both developed and less developed countries for the 1860-1963 period. As he notes, though, it is difficult to establish "with confidence the direction of the causal mechanism, i.e., of deciding whether financial factors were responsible for the acceleration of economic development or whether financial development reflected economic growth whose mainsprings must be sought elsewhere" (p. 48). And indeed Jung (1986) provides postwar econometric evidence for a group of 56 countries that causality (in the

\footnotetext{
${ }^{1}$ The evidence that early stages of growth are accompanied by a worsening of the income distribution is by no means clear-cut. Korea, e.g., grew very fast over the 196585 period. While income inequality did worsen slightly among rural households over this period, a bigger improvement took place in the distribution of income among urban households (Dornbusch and Park 1987, table 8).
} 
Granger sense) runs in either and both ways. Finally, historical case studies such as those undertaken in Cameron (1967) have stressed the key importance of financial factors in the economic development of several European countries.

The current analysis focuses on economic growth, institutional development, and the distribution of income. Economic growth fosters investment in organizational capital, which in turn promotes further growth. In the model, institutions arise endogenously to facilitate trade in the economy, and they do so in two ways: First, trading organizations allow for a higher expected rate of return on investment to be earned. In particular, in the environment modeled, information is valuable since it allows investors to learn about the aggregate state of technology. Through a research-type process, intermediaries collect and analyze information that allows investors' resources to flow to their most profitable use. By investing through an intermediary, individuals gain access, so to speak, to a wealth of experience of others. While Boyd and Prescott (1986) also stress the role that intermediaries can play in overcoming information frictions, the nature of these frictions is different. Second, trading organizations also play the traditional role of pooling risks across large numbers of investors. Townsend (1978) highlights the insurance role of intermediaries, but not their role in allowing a more efficient allocation of resources for production. Thus by investing through intermediated structures, individuals obtain both a higher and a safer return.

As in Townsend $(1978,1983 b)$, investment in organizational capital is costly. Consequently, high-income economies are better disposed to undertake such financial superstructure building than ones with lowincome levels. The development of financial superstructure, since it allows a higher return to be earned on capital investment, in turn feeds back on economic growth and income levels. In this latter regard, the current analysis is a close cousin of Townsend (1983a), which also examines the relationship between financial structure and economic activity, although within the context of a framework in which the extent of financial markets is exogenously imposed and that abstracts from the issue of growth. Also, in the spirit of recent work by Romer (1986), Rebelo (1987), and Lucas (1988), growth is modeled as an endogenous process; that is, it does not depend on exogenous technological change.

The dynamics of the development process resemble the Kuznets (1955) hypothesis. In the early stages of development, an economy's financial markets are virtually nonexistent and it grows slowly. Financial superstructure begins to form as the economy approaches the intermediate stage of the growth cycle. Here the economy's growth and savings rates both increase, and the distribution of income across 
the rich and poor widens. By maturity, the economy has developed an extensive structure for financial intermediation. In the final stage of development the distribution of income across agents stabilizes, the savings rate falls, and the economy's growth rate converges (although perhaps nonmonotonically) to a higher level than that prevailing during its infancy. According to Lindert and Williamson (1985, pp. 34243), "it is exactly this kind of correlation-rising inequality coinciding with rising savings and accumulation rates during Industrial Revolutions-that encouraged the trade-off belief [between growth and inequality] among classical economists who developed their growth models while the process was underway in England."

\section{The Economic Environment}

Consider an economy populated by a continuum of agents distributed over the interval $[0,1]$ with Lebesgue measure $\lambda$. An agent's goal in life is to maximize his expected lifetime utility as given by

$$
\underset{0}{E}\left[\sum_{t=0}^{\infty} \beta^{t} \ln c_{t}\right] \text { with } 0<\beta<1,
$$

where $c_{t}$ is his period $t$ consumption flow and $\beta$ the discount factor.

Each agent is entitled to operate one or both of two linear production technologies. The first offers a safe but relatively low return on investment. Here $i_{t-1}$ units of capital invested at the end of period $t-$ 1 yield $\delta i_{t-1}$ units of output in period $t$, or $y_{t}$. Thus, more formally, $y_{t}=\delta i_{t-1}$, where $\delta$ is a technological constant. The second investment opportunity yields a higher (unconditional) expected return but is more risky. Specifically, with this technology, production is governed by the process $y_{t}=\left(\theta_{t}+\epsilon_{t}\right) i_{t-1}$, where $\theta_{t}+\epsilon_{t}$ represents a composite technology shock. Each technology can be operated only once by the individual in a period. Now, at the beginning of each period $t$, an agent will have a certain amount of wealth, $k_{t}$, at his disposal. This wealth either can be used for current consumption or can be invested in capital for use in production next period. Individuals are heterogeneous in the sense that their stocks of capital in any given period may differ. At the start of time, each agent is endowed with a certain amount of goods or capital, $k_{0}$. The initial distribution of wealth in the society is represented by the cumulative distribution function $\hat{H}_{0}: \mathbb{R}_{++} \rightarrow[0,1]$.

The period $t$ technological shock has two components. The first component, $\theta_{t}$, represents an aggregate disturbance and thus is common across technologies, while the second, $\epsilon_{t}$, portrays an individual(or project-) specific shock. All that an agent can costlessly observe is the realized composite rate of return $\theta_{t}+\epsilon_{t}$ on his own project. The 
stochastic structure of the economic environment will be delimited in the following way.

Assumption A. The aggregate shock $\theta_{t}$ is governed by the timeinvariant distribution function $F\left(\theta_{t}\right)$. Let $\Theta=[\underline{\theta}, \bar{\theta}] \subset \mathbb{R}_{++}$and $F$ : $\Theta \rightarrow[0,1]$. Furthermore, suppose that $E[\ln [\phi \theta+(1-\phi) \delta]]=$ $\int\{\ln [\phi \theta+(1-\phi) \delta]\} d F(\theta)>\ln \delta>-\ln \beta$ for all $\phi \in[0,1]$; by Jensen's inequality, this implies $E[\theta]>\delta>1 / \beta$.

Assumption B. For each individual $j \in[0,1]$, the idiosyncratic shocks $\epsilon_{t}(j)$ are drawn from the distribution function $G\left(\epsilon_{t}(j)\right)$. Let $\Lambda=[\underline{\epsilon}, \bar{\epsilon}] \subset \mathbb{R}$ and $G: \Lambda \rightarrow[0,1]$. Additionally, assume that $E[\epsilon]=$ $\int \epsilon d G(\epsilon)=0$ and $\underline{\theta}+\underline{\epsilon}>0$.

As in Townsend $(1978,1983 b)$, it will be assumed that trading arrangements are costly to establish. Given that setting up organizational structures is costly, institution formation will be economized on. Imagine some collection of agents forming a coalition among themselves to collect and process information, coordinate production activity, and spread risk across projects. Specifically, let $A$ denote the set of $j \in[0,1]$ constituting the intermediary structure. First, it will be assumed that there is a once-and-for-all lump-sum cost of $\alpha$ associated with incorporating each agent $j$ into the trading syndicate. ${ }^{2}$ Thus on this account the total fixed cost associated with building the trading network would be $\alpha \int_{A} d \lambda(j)$. Second, suppose that each period there are costs incurred in proportion $1-\gamma$ to the amount of funds each agent invests in the syndicate. Consequently, if in a given period agent $j$ invests $i(j)$ units of capital in the cooperative, the total variable cost associated with running the financial structure would be $(1-\gamma) \times$ $\int_{A} i(j) d \lambda(j)$. Clearly, if trading arrangements are ever to emerge, these proportional costs cannot be too high. To ensure that in the subsequent analysis they will not be prohibitively large, the following assumption is made.

Assumption C. Let $\gamma, \delta$, and $F(\cdot)$ be specified such that $\int \theta d F(\theta)<$ $\int \gamma \max (\delta, \theta) d F(\theta)$.

Note that this assumption implies that the random variable $\gamma \max (\delta, \theta)$ stochastically dominates $\theta$ in the second-order sense and

${ }^{2}$ According to Townsend (1983b, p. 259), "the idea that trade links are costly, per se, seems to be a useful formalism, presumably capturing the cost of bookkeeping, the cost of enforcement, the cost of monitoring when there is imperfect information, the physical cost of exchange (transportation), the difficulties of communication, and so on." For instance, each party to an agreement may have to hire lawyers or accountants to advise on its details, pay the cost of installing communication devices (computers, liaisons, or transportation terminals), or simply incur the educational expenses involved with learning new business procedures etc. 
is automatically satisfied when $\gamma=1$ (no proportional transactions costs). ${ }^{3}$

There are three potential benefits from establishing networks. First, information has a public-good aspect to it. Each entrepreneur desires information on the realized project returns of others. This would allow his production decisions to be better made since such realized returns contain useful information about the magnitude of the aggregate shock. Even if such information was public knowledge, no individual entrepreneur would want to produce first since by waiting he would gain the experience of others. Thus there is a coordination problem inherent in individual entrepreneurs' production planning that trading agreements may be able to overcome. Second, trading mechanisms could potentially be used to diversify away the idiosyncratic risk associated with individual production projects. Third, they may allow an agent better opportunities for transferring consumption across time through arrangements for borrowing and lending. The emergence of such trading arrangements is the subject of the next section.

\section{Competitive Equilibrium}

\section{Financial Intermediation}

Many organizational structures can be decentralized with a subset of agents acting as go-betweens who intermediate economic activity for some larger set of individuals. They charge competitively determined fees for this service. Suppose that in period $t-1$ some individual in the economy has assumed (at a cost of $\alpha$ ) the role of being an intermediary for a set of agents $A_{t-1}$ with positive measure. This go-

${ }^{3}$ To see this, let $\xi \equiv \gamma \max (\delta, \theta)$ and $H: \mathbb{R}_{+} \rightarrow[0,1]$ represent the distribution function governing $\xi$. Note that assumption $\mathrm{C}$ can now be written as assumption $\mathrm{C}^{\prime}$ :

$$
\int_{0}^{\infty}[1-H(\xi)] d \xi=\int_{0}^{\infty} \gamma \max (\delta, \theta) d F(\theta)>\int_{0}^{\infty} \theta d F(\theta)=\int_{0}^{\infty}[1-F(\theta)] d \theta,
$$

where $F$ has been extended to $\mathbb{R}_{+}$by defining $F(\theta)=0$ for $\theta \in[0, \theta)$ and $F(\theta)=1$ for $\theta \in[\bar{\theta}, \infty)$. For $\xi$ to be larger than $\theta$ in the sense of second-order stochastic dominance, it must happen that $\int_{0}^{x}[F(t)-H(t)] d t \geq 0$ for all $x \in \mathbb{R}_{+}$, with strict equality obtaining for some $x$ (Hadar and Russell 1971, definition 2). To show this, observe that (i) $H(t)<F(t)$ for $0<t<\gamma \delta$ since $H(t)=0<F(t)$ and (ii) $H(t)>F(t)$ for all $t \geq \gamma \delta$ since $H(t)=F(t / \gamma)>F(t)$. Now consider the expression $\int_{0}^{x}[F(t)-H(t)] d t$. For $x \leq \gamma \delta$, this is clearly positive since $F(t)>H(t)$ by observation i. For $x \geq \gamma \delta$, rewrite this expression as $\int_{0}^{\gamma \delta}[F(t)-H(t)] d t+\int_{\gamma \delta}^{x}[F(t)-H(t)] d t$. Here, by $\mathrm{i}$ and ii, the first term is positive while the second is negative. But assumption $C^{\prime}$ guarantees that the first term always dominates since $\int_{0}^{\infty}[F(t)-H(t)] d t>0$ so that $\int_{0}^{\gamma \delta}[F(t)-H(t)] d t>-\int_{\gamma \delta}^{\infty}[F(t)-$ $H(t)] d t>-\int_{\gamma \delta}^{x}[F(t)-H(t)] d t$. 
between offers the following service: In exchange for a once-and-forall fee of $q$ plus the rights to operate an individual's project, the intermediary promises a return of $r\left(\theta_{t+\jmath}\right)$ per unit of capital invested in any period $t+j-1$, with the go-between absorbing all costs associated with trading. Needless to say, since the go-between's goal is to maximize profits, he will adopt the most efficient scheme possible for intermediation. In pursuit of this end, let the intermediary follow in every period the investment plan outlined below for period $t$.

To begin with, suppose that person $j$ invests $i_{t-1}(j)$ units of capital with the intermediary at the end of period $t-1$. Then the aggregate amount of capital (net of the proportional transactions costs) that the intermediary has to invest in $t$ from these deposits is $\gamma \times$ $\int_{A_{t-1}} i_{t-1}(j) d \lambda(j)$, where again $\lambda$ is the Lebesgue measure. Now, let the intermediary randomly select some finite number of high-risk/ return projects, say $\tau$, from the set $A_{t-1}$; denote this set of projects by $A_{t-1}^{e}$. Each of the "trial" projects selected is funded with the amount $\gamma K_{t}=\left[\gamma \int_{A_{t-1}} i_{t-1}(j) d \lambda(j)\right] /\left[\int_{A_{t-1}} d \lambda(j)\right]$. The intermediary then calculates the average net realized rate of return, $\hat{\theta}_{t \tau}$, on these projects, where formally ${ }^{4}$

$$
\hat{\theta}_{t \tau}=\frac{\gamma}{\tau}\left(\theta_{t} \tau+\sum_{m=1}^{\tau} \epsilon_{t m}\right)
$$

Now, if the "test statistic" $\hat{\theta}_{t \tau}$ is greater than $\gamma \delta$, then the remaining high-risk/return projects operated by the intermediary are each funded with $\gamma K_{t}$ units of capital; otherwise the go-between invests its resources in safe projects. ${ }^{5}$

Note that relative to the size of the intermediary's portfolio of projects, the number of production technologies chosen for research purposes is negligible. More precisely, the set of experimental projects, $A_{t-1}^{e}$, being countable has (Lebesgue) measure zero. Consequently, other than the important informational role these test projects play, they have a negligible impact on the profits earned by the intermediary. Thus the net rate of return on the intermediary's production activities, or $z\left(\theta_{t}, \hat{\theta}_{t \tau}\right)$, will be given by

\footnotetext{
${ }^{4}$ For the purpose of taking sums, reindex the (countable) collection of agents in the set $A^{e}$ by the natural numbers.

${ }^{5}$ Envision each period as consisting of two subintervals. In the first subinterval, production is undertaken. Production can occur at any time within this subinterval: some projects can be undertaken early, others late. The intermediary's trial projects are run early, the rest late. Agents who choose not to transact with an intermediary are indifferent about when to operate their projects within this subinterval since they cannot observe at that time what is happening to production elsewhere in the economy. In the second subinterval the output from production is distributed and agents decide how much to consume currently out of their proceeds and how much to invest for future consumption.
} 


$$
z\left(\theta_{t}, \hat{\theta}_{t \tau}\right)=\left\{\begin{array}{l}
\frac{\gamma \int_{A_{t-1}-A_{t-1}^{e}}\left[\theta_{t}+\epsilon_{t}(j)\right] d \lambda(j)+\hat{\theta}_{t \tau} \int_{A_{t-1}^{e}} d \lambda(j)}{\int_{A_{t-1}} d \lambda(j)}=\gamma \theta_{t}, \\
\text { if } \hat{\theta}_{t \tau}>\gamma \delta, \\
\frac{\gamma \delta \int_{A_{t-1}-A_{t-1}^{e}} d \lambda(j)+\hat{\theta}_{t \tau} \int_{A_{t-1}^{e}} d \lambda(j)}{\int_{A_{t-1}} d \lambda(j)}=\gamma \delta, \\
\text { if } \hat{\theta}_{t \tau} \leq \gamma \delta .
\end{array}\right.
$$

The following lemma can now be stated.

Lemma 1. As $\tau \rightarrow \infty, z\left(\theta_{t}, \hat{\theta}_{t \tau}\right) \rightarrow \gamma \max \left(\delta, \theta_{t}\right)$ almost surely.

Proof. For $x \in(-\gamma \delta, \infty)$, let $I(x)=1$ if $x>0$ and $I(x)=0$ otherwise. Then $z\left(\theta_{t}, \hat{\theta}_{t \tau}\right)$ can be expressed as

$$
z\left(\theta_{t}, \hat{\theta}_{t \tau}\right)=I\left(\hat{\theta}_{t \tau}-\gamma \delta\right) \gamma \theta_{t}+\left[1-I\left(\hat{\theta}_{t \tau}-\gamma \delta\right)\right] \gamma \delta .
$$

Clearly, if $\theta_{t}=\delta$, then $z\left(\theta_{t}, \hat{\theta}_{t \tau}\right)=\gamma \delta$, regardless of the value of $\hat{\theta}_{t \tau}$. Therefore, trivially, here $z\left(\theta_{t}, \hat{\theta}_{t \tau}\right)=\gamma \max \left(\delta, \theta_{t}\right)$. Suppose alternatively that $\theta_{t} \neq \delta$. Now as $\tau \rightarrow \infty, \hat{\theta}_{t \tau} \rightarrow \gamma \theta_{t}$ almost surely by assumption $B$ and the strong law of large numbers. This, though, implies that $I\left(\hat{\theta}_{t \tau}-\gamma \delta\right) \rightarrow I\left(\gamma \theta_{t}-\gamma \delta\right)$ almost surely since $I(\cdot)$ is a continuous function on $(-\gamma \delta, 0) \cup(0, \infty)$. Hence in the case in which $\theta_{t} \neq \delta$, it follows that $z\left(\theta_{t}, \hat{\theta}_{t \tau}\right) \rightarrow \gamma \max \left(\delta, \theta_{t}\right)$ almost surely as $\tau \rightarrow \infty$. Q.E.D.

In competitive equilibrium the profits realized from financial intermediation must be zero. This transpires since any agent in the economy (willing to incur the cost of $\alpha$ ) can establish himself as an intermediary. The zero profit condition for intermediation is

$$
\begin{aligned}
& {\left[\gamma \max \left(\delta, \theta_{t}\right)-r\left(\theta_{t}\right)\right] \int_{A_{t-1}} i_{t-1}(j) d \lambda(j)} \\
& +\gamma \max \left(\delta, \theta_{t}\right)(q-\alpha) \int_{A_{t-1}^{\prime}} d \lambda(j)=0,
\end{aligned}
$$

where $A_{t-1}^{\prime} \subseteq A_{t-1}$ represents the set of agents entering into an agreement with the go-between for the first time at $t-1$. This condition necessitates that $r\left(\theta_{t}\right)=\gamma \max \left(\delta, \theta_{t}\right)$ and $q=\alpha$, since it must hold for arbitrary $\int_{A_{t-1}} i_{t-1}(j) d \lambda(j) \geq 0$ and $\int_{A_{t-1}^{\prime}} d \lambda(j) \geq 0 .{ }^{6}$ Note that the

${ }^{6}$ Note here that it is being presumed that the intermediary commits himself forever to the policy of paying the return $r\left(\theta_{t}\right)$ in each period $t$ on any and all deposits made in $t-1$, subject only to the stipulation that the depositor has paid at some time the onceand-for-all fee of $q$. The possibility of default is precluded by assumption. Now suppose that, for some $\int_{A_{t-1}} i_{t-1}(j) d \lambda(j) \geq 0$ and $\int_{A_{t-1}^{\prime}} d \lambda(j) \geq 0$, condition (1) could become negative with positive probability. Then with positive probability, any intermediary could go bankrupt in the first period of its operation and would have to default on its obligations to depositors (since the intermediary would owe an infinitely large amount relative to his start-up wealth). This, though, is prohibited. Any agent can become an intermediary, rather than transact with one, if it is in his own best interest to do so. Alternatively, then, suppose that $r\left(\theta_{t}\right)$ and $q$ are such that (1) never becomes negative 
intermediary offers agents a rate of return on their investments that is (i) completely devoid of idiosyncratic production risk and (ii) safeguarded from the potential losses that could occur when the aggregate return on the risky technology falls below the opportunity cost of the resources committed. Also, investors are charged only a lumpsum fee that exactly compensates the go-between for the once-andfor-all cost of establishing a business arrangement with them. Finally, in line with Goldsmith (1969), intermediaries allocate resources to the place in the economic system in which they earn the highest return.

\section{Discussion}

The exact story of intermediation told is not crucial for the subsequent analysis. What is necessary is that intermediaries provide customers with a distribution of returns on their investments that both is preferred and has a higher mean. For instance, as in Freeman (1986), it could simply be assumed that there exists a technology that yields a superior return on investment but requires large minimum amounts of capital. ${ }^{7}$ This nonconvexity in project size would provide a rationale for individuals to pool funds. Alternatively, financial intermediaries may arise to service the liquidity needs of agents. Specifically, along the lines of Diamond and Dybvig (1983), suppose that agents face two investment opportunities: an illiquid investment that yields a high rate of return and a liquid one with a low yield. In a world with idiosyncratic risk, agents may be reluctant to save substantial parts of their wealth in an illiquid asset for fear that they may need to use these funds before the investment matures. Large financial intermediaries can calculate the average demand for early withdrawal due to idiosyncratic events and adjust their investment portfolios to accommodate this better than an individual saver can. Bencivenga and Smith (1988) model the effect that intermediaries can have on an economy's growth rate by encouraging a switch in savings from unproductive liquid assets to productive illiquid ones. Other work stresses the role that intermediaries play in overcoming informational frictions. For example, Boyd and Prescott (1986) focus on financial intermediary coalitions as an incentive-compatible mechanism for allocating resources to their most productive use in a world in which borrowers have private information about the potential worthiness of

and is strictly positive with nonzero probability. Here the intermediary could realize infinite profits in any particular period with positive probability and never realize any losses, a situation ruled out by the assumption of free entry into the industry.

${ }^{7}$ In a similar vein, Gertler and Rogoff (1989) assume that the probability that an investment project will attain a good return is an increasing function of the amount of funds invested. This again could provide a rationale for agents to pool funds. 
their investment projects. In principle, their framework could be incorporated into a growth model. Finally, Diamond (1984) and Williamson (1986) stress the importance of large intermediary structures for minimizing the costs to lenders (depositors) of monitoring the behavior of both borrowers and intermediary managers.

The current paper stresses the role that intermediaries play in collecting and analyzing information, thereby facilitating the migration of funds to the place in the economy in which they have the highest social return. The model of intermediation presented above could undoubtedly be generalized to capture reality better. For instance, industry-specific shocks could be introduced. Suppose that the risky technology now operates in several sectors. Let the risky technology be formulated as $y_{t}=\left[\theta_{t}+v_{t}(l)+\epsilon_{t}(j)\right] i_{t-1}$, where $\boldsymbol{v}_{t}(l)$ is a disturbance specific to industry $l$. Now through a sampling process analogous to that analyzed above, intermediaries could uncover $\theta_{t}+v_{t}(l)$ for each industry $l$. If the aggregate state of the economy warrantedthat is, if $\theta_{t}+v_{t}(l)>\gamma \delta$ for some $l$-the funds available would be directed to the sector(s) with the highest $v_{t}$. Otherwise, the resources would be invested in the safe technology (which would perhaps be better labeled in the current context as an "industry").

\section{Market Participation}

Not all agents may find the terms of the investment contract offered currently attractive. In particular, for some agents it may not be worthwhile to pay a lump-sum fee of $q$ in order to gain permanent access to the intermediation technology paying a random return of $r\left(\theta_{t}\right)$ in each $t$. Thus it is natural at this point to examine the determination of participation in the exchange network. To do this, consider the decision making of an individual in period $t$ who is currently outside of the intermediated sector. His actions in this period are summarized by the outcome of the following dynamic programming problem:

$$
\begin{array}{r}
w\left(k_{t}\right) \\
=\max _{s_{t}, \phi_{t}}\left\{\ln \left(k_{t}-s_{t}\right)+\beta \int \max \left[w\left(s_{t}\left(\phi_{t}\left(\theta_{t+1}+\epsilon_{t+1}\right)+\left(1-\phi_{t}\right) \delta\right)\right),\right.\right. \\
\left.\left.v\left(s_{t}\left(\phi_{t}\left(\theta_{t+1}+\epsilon_{t+1}\right)+\left(1-\phi_{t}\right) \delta\right)-q\right)\right] d F\left(\theta_{t+1}\right) d G\left(\epsilon_{t+1}\right)\right\},
\end{array}
$$

where $s_{t}$ is the agent's period $t$ saving level, $\phi_{t}$ the fraction of his portfolio invested in the high-risk/return technology, and $v\left(s_{t}\left(\phi_{t}\left(\theta_{t+1}\right.\right.\right.$ $\left.\left.\left.+\epsilon_{t+1}\right)+\left(1-\phi_{t}\right) \delta\right)-q\right)$ represents the expected lifetime utility the 
agent would realize in $t+1$ if he then entered the intermediated sector with $s_{t}\left(\phi_{t}\left(\theta_{t+1}+\epsilon_{t+1}\right)+\left(1-\phi_{t}\right) \delta\right)-q$ units of capital at his disposal. ${ }^{8}$ It can be demonstrated that $w$ is a continuous and increasing function for any function $v$ sharing these properties; it will be uniquely determined as well (see Stokey, Lucas, and Prescott 1989). Note that problem ( $\mathrm{P} 1)$ presumes that in $t+1$ the agent will enter or remain outside of the intermediated sector depending on which choice then yields the highest expected utility. Hence, $w\left(k_{t}\right)$ gives the maximum lifetime utility an individual with $k_{t}$ units of capital can expect in period $t$ if he chooses not to participate in the exchange network just then.

Likewise, the dynamic programming problem for any agent currently within the intermediated sector is given by ${ }^{9}$

$v\left(k_{t}\right)=\max _{s_{t}}\left\{\ln \left(k_{t}-s_{t}\right)+\beta \int \max \left[w\left(s_{t} r\left(\theta_{t+1}\right)\right), v\left(s_{t} r\left(\theta_{t+1}\right)\right)\right] d F\left(\theta_{t+1}\right)\right\}$.

If $w$ is a continuous and increasing function, then $v$ inherits these traits as well. Thus (P1) and (P2) jointly define the pair of functions $w$ and $v$. Specifically, consider the vector function $(w, v)$. Then $(\mathrm{P} 1)$ and (P2) define a mapping $\Omega$ such that $(w, v)=\Omega(w, v)$. It is easy to establish that the operator $\Omega$ is a contraction in the space of continuous vector functions with norm $\max \left[\sup _{x}|w(x)|, \sup _{x}|v(x)|\right]$ and consequently has a unique fixed point.

Presumably, in any period $t$, a given endowment of capital, $k_{t}$, is worth more to an agent operating within the intermediated sector than to one outside of it; that is, $v\left(k_{t}\right)>w\left(k_{t}\right)$. This should transpire since exchange with the go-between yields a better distribution of returns per unit of capital invested than autarky does. If this is so, then

${ }^{8}$ Throughout the analysis, it will be implicitly assumed that the constraints $s_{t} \in\left[0, k_{t}\right]$ and $\phi_{t} \in[0,1]$ apply, as relevant, to the optimization problems formulated.

${ }^{9}$ Problem (P2) assumes that agents participating in the intermediated sector will invest all their savings with the go-between. Strictly speaking, the intermediary requires the use of only one safe technology and a countable infinity of the high-risk/return ones. Thus it may seem reasonable to allow some agents to make individual isolated use of the unneeded technologies so as to economize on the proportional transactions costs associated with intermediated activity. It is easily demonstrated, with eqq. (A5) and (A6) in the Appendix, that the following assumption, D, ensures that such options, even if available, would never be executed:

$$
\text { For all } \phi \in[0,1], \int \frac{\phi \theta+(1-\phi) \delta}{\gamma \max (\theta, \delta)} d F(\theta)<1 \text {. }
$$

Note that this assumption holds automatically when $\gamma=1$ (i.e., no proportional transactions costs). Finally, assumptions $\mathrm{C}$ and $\mathrm{D}$ can be guaranteed by imposing the single restriction that $E[\theta] E[1 /[\gamma \max (\delta, \theta)]]<1$. 
once an individual enters the intermediated sector, he will never leave it. This conjecture will now be tested.

If it is true, the functional equation (P2) could be simplified to allow $v$ to be defined without reference to $w$. Specifically, (P2) would now read

$$
v\left(k_{t}\right)=\max _{s_{t}}\left[\ln \left(k_{t}-s_{t}\right)+\beta \int v\left(s_{t} r\left(\theta_{t+1}\right)\right) d F\left(\theta_{t+1}\right)\right] .
$$

Furthermore, given the logarithmic form of the utility function, it is straightforward to establish that the value function $v\left(k_{t}\right)$ and the policy rule $s_{t}=s\left(k_{t}\right)$ would have the following simple forms:

$$
\begin{aligned}
v\left(k_{t}\right)= & \frac{1}{1-\beta} \ln (1-\beta)+\frac{\beta}{(1-\beta)^{2}} \ln \beta \\
& +\frac{\beta}{(1-\beta)^{2}} \int \ln r(\theta) d F(\theta)+\frac{1}{1-\beta} \ln k_{t}
\end{aligned}
$$

and

$$
s\left(k_{t}\right)=\beta k_{t} .
$$

Thus agents within the intermediated sector would save a constant fraction of their wealth each period. Given the solution for $v$, problem (P1) then implies a solution for $w$. If it can be established that the implied solution for $w$ is such that $w \leq v$, then the solution for $(w, v)$ has been found. Toward this end, assume that $v$ is given by (2).

LEMMA 2. $v(k)>w(k)$.

Proof. Let $w^{j+1} \equiv T w^{j}$, where the operator $T$ is defined by

$$
\begin{gathered}
T w^{\jmath}=\max _{s^{\jmath}, \phi^{\jmath}}\left\{\ln \left(k-s^{\jmath}\right)+\beta \int \max \left[w^{\jmath}\left(s^{j}\left(\phi^{\jmath}(\theta+\epsilon)+\left(1-\phi^{\jmath}\right) \delta\right)\right),\right.\right. \\
\left.\left.v\left(s^{\jmath}\left(\phi^{\jmath}(\theta+\epsilon)+\left(1-\phi^{\jmath}\right) \delta\right)-q\right)\right] d F(\theta) d G(\epsilon)\right\} .
\end{gathered}
$$

Now consider the sequence of functions $\left\{w^{\jmath}\right\}_{j=0}^{\infty}$. Denote the optimal policy functions associated with the mapping above by $\tilde{s}^{\jmath}$ and $\tilde{\phi}^{\jmath}$. The proof will proceed by induction. First, it will be demonstrated that if $w^{j} \leq v$, then $w^{j+1}<v$. Second, to start the induction hypothesis, a $w^{0}$ will be chosen such that $w^{0}<v$. Thus $w=\lim _{j \rightarrow \infty} w^{j}<v$.

Suppose $w^{\jmath} \leq v$. Then

$$
\begin{aligned}
v-w^{\jmath+1} \geq[ & \left.\ln \left(k-\tilde{s}^{\jmath}\right)+\beta \int v\left(\tilde{s}^{\jmath} r(\theta)\right) d F(\theta)\right] \\
- & \left\{\ln \left(k-\tilde{s}^{\jmath}\right)+\beta \int \max \left[w^{\jmath}\left(\tilde{s}^{\jmath}\left(\tilde{\phi}^{\jmath}(\theta+\epsilon)+\left(1-\tilde{\phi}^{\jmath}\right) \delta\right)\right),\right.\right. \\
& \left.\left.v\left(\tilde{s}^{\jmath}\left(\tilde{\phi}^{\jmath}(\theta+\epsilon)+\left(1-\tilde{\phi}^{J}\right) \delta\right)-q\right)\right] d F(\theta) d G(\epsilon)\right\}
\end{aligned}
$$

since the savings rule $\tilde{s}^{j}$ is suboptimal for the program (P3). Next, by the induction hypothesis, $w^{j} \leq v$ so that 


$$
\begin{aligned}
v-w^{j+1}> & \beta \int v\left(\tilde{s}^{\jmath} r(\theta)\right) d F(\theta) \\
& -\beta \int v\left(\tilde{s}^{\jmath}\left(\tilde{\phi}^{\jmath}(\theta+\epsilon)+\left(1-\tilde{\phi}^{\jmath}\right) \delta\right)\right) d F(\theta) d G(\epsilon) .
\end{aligned}
$$

This can be rewritten in light of (2) and Jensen's inequality as

$$
\begin{aligned}
v-w^{j+1}> & \beta \int v\left(\tilde{s}^{j} r(\theta)\right) d F(\theta) \\
& -\beta \int v\left(\tilde{s}^{j}\left(\tilde{\phi}^{j} \theta+\left(1-\tilde{\phi}^{j}\right) \delta\right)\right) d F(\theta) \geq 0 .
\end{aligned}
$$

The nonnegative sign of this expression obtains since the random variable $r(\theta)=\gamma \max (\delta, \theta)$ stochastically dominates $\theta$ in the secondorder sense by assumption C. ${ }^{10}$ Finally, to start the induction hypothesis, let $w^{0}(k)=[1 /(1-\beta)] \ln (1-\beta)+\left[\beta /(1-\beta)^{2}\right] \ln \beta+[1 /(1$ $-\beta)] \ln k$. Then $v(k)-w^{0}(k)=\left[\beta \gamma /(1-\beta)^{2}\right] \int \ln \max (\delta, \theta) d F(\theta)>0$. Q.E.D.

The extent of participation in the exchange network is now easily characterized. Consider some arbitrary set of agents for whom it was not in their individual interests to engage in trade with the intermediary up until the current period $t$. (This set of agents could be all or none of the actors in the economy.) Each of these individuals must now decide on whether or not to join the market sector. Given that the cost of accessing the intermediary is lump-sum, it seems likely that agents with a capital stock falling below some minimal level $\underline{k}>0$ will remain outside of the exchange network, while those having an endowment exceeding some upper threshold level $\bar{k} \geq \underline{k}$ will join.

Lemma 3. There exist $\underline{k}$ and $\bar{k}$, with $0<\underline{k} \leq \bar{k}$, such that $v\left(k_{t}-q\right)<$ $w\left(k_{t}\right)$ for $0<k_{t}<\underline{k}$ and $v\left(k_{t}-q\right)>w\left(k_{t}\right)$ for $k_{t}>\bar{k}$.

Proof. Since both $w(k)$ and $v(k)$ are continuous functions in $k$, it is enough to demonstrate that (i) $\lim _{k \rightarrow q}[w(k)-v(k-q)]>0$ and (ii) $\lim _{k \rightarrow \infty}[w(k)-v(k-q)]<0$. To show part i, note on the one hand that, from equation (2), $\lim _{k \rightarrow q} v(k-q)=-\infty$. On the other hand, though, it is feasible never to join the coalition and pursue the following dynamic program:

$w^{0}(k)=\max _{s, \phi}\left[\ln (k-s)+\beta \int w^{0}(s(\phi(\theta+\epsilon)+(1-\phi) \delta)) d F(\theta) d G(\epsilon)\right]$.

It is easy to show that the value function $w^{0}(k)$ and the policy rules $s=s(k)$ and $\phi=\phi(k)$ have the following simple forms:

$$
\begin{aligned}
w^{0}(k)= & \frac{1}{1-\beta} \ln (1-\beta)+\frac{\beta}{(1-\beta)^{2}} \ln \beta+\frac{\beta}{(1-\beta)^{2}} \\
& \times \int \ln [c(\theta+\epsilon)+(1-c) \delta] d F(\theta) d G(\epsilon)+\frac{1}{1-\beta} \ln k,
\end{aligned}
$$

\footnotetext{
${ }^{10}$ See Hadar and Russell (1971, theorem 2) for more detail.
} 


$$
s(k)=\beta k
$$

(compare [2] and [3]), and

$$
\phi(k)=c>0,
$$

with the constant $c \in(0,1]$ solving the condition $\int(\theta+\epsilon-\delta) /[c(\theta+$ $\epsilon)+(1-c) \delta] d F(\theta) d G(\epsilon) \geq 0 .{ }^{11}$ Clearly, $w(k) \geq w^{0}(k)>-\infty$ (by assumptions $\mathrm{A}$ and $\mathrm{B}$ ) for all $k>0$.

To establish part ii, observe that problem (P1) and lemma 2 imply $w(k) \leq \max _{s, \phi}\left[\ln (k-s)+\beta \int v(s(\phi(\theta+\epsilon)+(1-\phi) \delta)) d F(\theta) d G(\epsilon)\right]$, which together with (P3) yields that

$$
\begin{aligned}
& w(k)-v(k-q) \\
& \leq \max _{s, \phi}\left[\ln (k-s)+\beta \int v(s(\phi(\theta+\epsilon)+(1-\phi) \delta)) d F(\theta) d G(\epsilon)\right] \\
& -\max _{s}\left[\ln (k-q-s)+\beta \int v(\operatorname{sr}(\boldsymbol{\theta})) d F(\theta)\right] .
\end{aligned}
$$

Next, given the logarithmic form of the value function, $v(\cdot)$, the first term in brackets is maximized by setting $s=\beta k$ and $\phi=c$ (compare [5] and [6]). These policy rules are also feasible choices for the second term in brackets provided that $k>q /(1-\beta)$. Thus, for $k>q /(1-\beta)$,

$$
\begin{aligned}
& w(k)-v(k-q) \\
& \leq \ln [k(1-\beta)]+\beta \int v(\beta k(c(\theta+\epsilon)+(1-c) \delta)) d F(\theta) d G(\epsilon) \\
& \quad-\ln [k(1-\beta)-q]-\beta \int v(\beta k(\operatorname{cr}(\theta)+(1-c) \delta)) d F(\theta) .
\end{aligned}
$$

Since $v(\cdot)$ is concave, by Jensen's inequality,

$$
\begin{gathered}
w(k)-v(k-q) \leq \ln \left[\frac{k(1-\beta)}{k(1-\beta)-q}\right] \\
+\beta \int[v(\beta k(c \theta+(1-c) \delta))-v(\beta k(\operatorname{cr}(\theta)+(1-c) \delta))] d F(\theta) .
\end{gathered}
$$

Consequently, $\lim _{k \rightarrow \infty}[w(k)-v(k-q)]<0$ since, first, $\lim _{k \rightarrow \infty} \ln \{k(1$ $-\beta) /[k(1-\beta)-q]\}=0$ and, second, $\beta \int[v(\beta k(c \theta+(1-c) \delta))-$ $v(\beta k(\operatorname{cr}(\theta)+(1-c) \delta))] d F(\theta)<0$ because $r(\theta)$ stochastically dominates $\theta$ by assumption $C$ and the expression behind the integral sign does not depend on $k$. Q.E.D.

\footnotetext{
${ }^{11}$ Some more detail on the derivation of the constant $c$ may be warranted. Suppose that (4) specifies $w^{0}$. Then the following conditions govern the solution for $\phi$ in $(\mathrm{P} 4)$ : (i) $\int(\theta+\epsilon-\delta) /[\phi(\theta+\epsilon)+(1-\phi) \delta] d F(\theta) d G(\epsilon) \leq 0$ if $\phi=0$; (ii) if $\phi \in(0,1), \int(\theta+$ $\epsilon-\delta) /[\phi(\theta+\epsilon)+(1-\phi) \delta] d F(\theta) d G(\epsilon)=0$; and (iii) $\int(\theta+\epsilon-\delta) /[\phi(\theta+\epsilon)+$ $(1-\phi) \delta] d F(\theta) d G(\epsilon) \geq 0$ if $\phi=1$. Clearly, the solution for $\phi$ does not depend on $k$; i.e., $\phi=c$, where $c$ is a constant. It is easy to deduce that $c \neq 0$. Evaluating condition $\mathrm{i}$ at $\phi=0$ yields $\int(\theta+\epsilon-\delta) / \delta d F(\theta) d G(\epsilon)>0$, which contradicts assumptions $\mathrm{A}$ and $\mathrm{B}$.
} 
Remark.-If $v(k-q)-w(k)$ is strictly increasing in $k$, then $\underline{k}=\bar{k}$. In general, though, this result does not appear to transpire.

Now define the sets $B^{c}$ and $B$ in the following manner:

$$
B^{c}=\left\{k_{t}: v\left(k_{t}-q\right)<w\left(k_{t}\right)\right\}, \quad B=\left\{k_{t}: v\left(k_{t}-q\right) \geq w\left(k_{t}\right)\right\} .
$$

By lemma 3 , the sets $B^{c}$ and $B$ are nonempty. Also, $\underline{k}=\inf B$ and $\bar{k}=$ $\sup B^{c}$. Clearly, it is in the interest of those individuals who have a capital stock $k_{t} \in B$ to establish a trading link with the go-between, but not so for those agents with an endowment $k_{t} \in B^{c}$. Equally as evident, it is possible to have a competitive equilibrium prevailing in period $t$ in which some agents choose to participate in the market sector and others choose to remain outside; this will depend on the distribution of capital across individuals who were outside of the trading network in $t-1$.

\section{Equilibrium}

To summarize the discussion so far, it has been shown that there exists a competitive equilibrium of the form defined below.

Definition. A competitive equilibrium is a set of value functions, $v\left(k_{t}\right)$ and $w\left(k_{t}\right)$, savings rules, $s\left(k_{t}\right)$ and $\phi\left(k_{t}\right)$, and pricing functions, $r\left(\theta_{t+1}\right)$ and $q$, such that

(i) For agents participating in the market sector, the functions $v\left(k_{t}\right)$ and $s\left(k_{t}\right)$ solve problem (P2), given $w\left(k_{t}\right)$ and $r\left(\theta_{t+1}\right)$. Individuals choose to remain or not in this sector in period $t$ depending on whether $v\left(k_{t}\right) \gtrless w\left(k_{t}\right)$. (It was demonstrated in lemma.2 that $v\left(k_{t}\right)>w\left(k_{t}\right)$, which caused entry into the market sector to become permanent. This lemma also implied that problem [P2] could be reduced to [P3], which has the solution $s\left(k_{t}\right)=\beta k_{t}$.)

(ii) For individuals in the nonmarket sector, the functions $w\left(k_{t}\right)$, $s\left(k_{t}\right)$, and $\phi\left(k_{t}\right)$ solve problem (P1), given $v\left(k_{t}\right), r\left(\theta_{t+1}\right)$, and $q$. Agents choose to transact or not with an intermediary in $t$ depending on whether $v\left(k_{t}-q\right) \gtrless w\left(k_{t}\right)$. (Lemma 3 establishes the existence of two nonempty sets $B$ and $B^{c}$ such that, for $k \in B$, $v(k-q) \geq w(k)$, while for $k \in B^{c}, w(k)>v(k-q)$. Thus it is possible to have a competitive equilibrium in which some agents participate in the market sector and others do not.)

(iii) All intermediaries earn zero profits in accord with (1), paying a rate of return $r\left(\theta_{t+1}\right)=\gamma \max \left(\delta, \theta_{t+1}\right)$ and charging a membership fee $q=\alpha$. (Any intermediary with positive measure can effectively access the technology $y_{t+1}=\gamma \max \left(\delta, \theta_{t+1}\right) i_{t}$, as was shown in lemma 1.$)^{12}$

\footnotetext{
${ }^{12}$ In competitive equilibrium the goods markets always clear since, for each agent, consumption plus physical investment in capital (inclusive of transactions costs) equals his endowment of output.
} 
The following proposition concludes this section.

Proposition 1 . The allocations generated by the competitive equilibrium defined above are Pareto optimal.

Proof. See the Appendix.

Remark. - Note that in the competitive equilibrium modeled, members of the nonmarket sector can effectively borrow from intermediaries at the market rate of return of $r\left(\theta_{t+1}\right)$ in order to finance entry into the market sector at time $t$; this opportunity affords no benefits, however.

\section{Savings, Growth, Development, and Income Distribution}

Some of the model's predictions about savings, growth, development, and income distribution will now be presented. To begin with, it will be demonstrated that economies in phases of development in which institutional infrastructure building is occurring will tend to have high rates of savings. This occurs since the construction of economic organization is expensive; specifically, it costs $\alpha$ to incorporate each individual into an institutional arrangement. Recall that those agents transacting in the intermediated sector save the amount $s_{t}=\beta k_{t}$. Individuals outside the trading network save in accord with the following dynamic program (see [P1] and [7]):

$$
\begin{aligned}
& w\left(k_{t}\right)=\max _{s_{t}, \phi_{t}}\left[\ln \left(k_{t}-s_{t}\right)\right. \\
& \quad+\beta \int_{D^{c}\left(s_{t}, \phi_{t}\right)} w\left(s_{t}\left(\phi_{t}\left(\theta_{t+1}+\epsilon_{t+1}\right)+\left(1-\phi_{t}\right) \delta\right)\right) d F\left(\theta_{t+1}\right) d G\left(\epsilon_{t+1}\right) \\
& \left.+\beta \int_{D\left(s_{t}, \phi_{t}\right)} v\left(s_{t}\left(\phi_{t}\left(\theta_{t+1}+\epsilon_{t+1}\right)+\left(1-\phi_{t}\right) \delta\right)-q\right) d F\left(\theta_{t+1}\right) d G\left(\epsilon_{t+1}\right)\right],
\end{aligned}
$$

where $D^{c}\left(s_{t}, \phi_{t}\right)=\left\{\left(\theta_{t+1}, \epsilon_{t+1}\right): s_{t}\left(\phi_{t}\left(\theta_{t+1}+\epsilon_{t+1}\right)+\left(1-\phi_{t}\right) \delta\right) \in B^{c}\right\}$ and $D\left(s_{t}, \phi_{t}\right)=\left\{\left(\theta_{t+1}, \epsilon_{t+1}\right): s_{t}\left(\phi_{t}\left(\theta_{t+1}+\epsilon_{t+1}\right)+\left(1-\phi_{t}\right) \delta\right) \in B\right\}$. Now denote the decision rules governing optimal savings and portfolio allocation in problem (P5) by $s_{t}=s\left(k_{t}\right)$ and $\phi_{t}=\phi\left(k_{t}\right)$. These individuals will save an amount $s\left(k_{t}\right)$ that is greater than $\beta k_{t}$ since they expect at some future date to incur the lump-sum cost $q$ of developing a link with the exchange system.

Proposition 2. $s\left(k_{t}\right)>\beta k_{t}$.

Proof. The proof proceeds by induction. Consider the sequence of functions $\left\{w^{j}\right\}_{j=0}^{\infty}$ and $\left\{s^{j}\right\}_{j=0}^{\infty}$ generated from the mapping $w^{j}=$ $T w^{j-1}$, with the operator $T$ defined by 


$$
\begin{aligned}
T w^{\jmath-1}= & \max _{s^{\jmath-1}}\left[\ln \left(k-s^{\jmath-1}\right)\right. \\
& +\beta \int_{D^{c}(s, \phi)} w^{\jmath-1}\left(s^{\jmath-1}(\phi(\theta+\epsilon)+(1-\phi) \delta)\right) d F(\theta) d G(\epsilon) \\
& \left.+\beta \int_{D(s, \phi)} v\left(s^{\jmath-1}(\phi(\theta+\epsilon)+(1-\phi) \delta)-q\right) d F(\theta) d G(\epsilon)\right] .
\end{aligned}
$$

Observe that the mapping $T$ depends on the values for $s$ and $\phi$ specified by (P5); that is, here $s$ and $\phi$ are being taken as exogenously given constants invariant with the value of $k$ in (8). Given the fixity of the sets $D^{c}(s, \phi)$ and $D(s, \phi)$, the operator $T$ maps concave functions into strictly concave ones. The efficiency condition governing the optimal choice of $s^{\jmath^{-1}}$ in the mapping above is

$$
\begin{aligned}
\frac{1}{k-s^{\jmath-1}}= & \beta \int_{D^{c}(s, \phi)}[\phi(\theta+\epsilon)+(1-\phi) \delta] \\
& \times w_{k}^{\jmath-1}\left(s^{\jmath-1}(\phi(\theta+\epsilon)+(1-\phi) \delta)\right) d F(\theta) d G(\epsilon) \\
& +\beta \int_{D(s, \phi)}[\phi(\theta+\epsilon)+(1-\phi) \delta] \\
& \times v_{k}\left(s^{\jmath-1}(\phi(\theta+\epsilon)+(1-\phi) \delta)-q\right) d F(\theta) d G(\epsilon) .
\end{aligned}
$$

It is easy to show that the operator $T$ is a contraction whose fixed point defined by $w=T w$ is characterized by (P5). ${ }^{13}$ Thus given any

${ }^{13}$ Briefly, the Euler equation connected with problem (P5) is

$\frac{1}{k-s(k)}=$

$$
\begin{aligned}
\beta \int_{D^{c}(s(k), \phi(k))} & \frac{\{\phi(k)(\theta+\epsilon)+[1-\phi(k)] \delta\} d F(\theta) d G(\epsilon)}{[s(k)\{\phi(k)(\theta+\epsilon)+[1-\phi(k)] \delta\}-s(s(k)\{\phi(k)(\theta+\epsilon)+[1-\phi(k)] \delta\})]} \\
+ & \beta \int_{D(s(k), \phi(k))} \frac{\phi(k)(\theta+\epsilon)+[1-\phi(k)] \delta}{(1-\beta)(s(k)\{\phi(k)(\theta+\epsilon)+[1-\phi(k)] \delta\}-q)} d F(\theta) d G(\epsilon),
\end{aligned}
$$

with $s(k)$ denoting the optimal policy function. Now consider the fixed point associated with the mapping shown by (8). Here the sets $D^{c}(s(k), \phi(k))$ and $D(s(k), \phi(k))$ are fixed, as far as the implied maximization is concerned. The choice problem underlying this mapping has the following Euler equation:

$$
\begin{aligned}
& \frac{1}{k-\tilde{s}(k)}= \\
& \beta \int_{D^{c}(s(k), \phi(k))} \frac{\{\phi(k)(\theta+\epsilon)+[1-\phi(k)] \delta\} d F(\theta) d G(\epsilon)}{[\tilde{s}(k)\{\phi(k)(\theta+\epsilon)+[1-\phi(k)] \delta\}-s(\tilde{s}(\tilde{k})\{\phi(k)(\theta+\epsilon)+[1-\phi(k)] \delta\})]} \\
&+\beta \int_{D(s(k), \phi(k))} \frac{\phi(k)(\theta+\epsilon)+[1-\phi(k)] \delta}{(1-\beta)(\tilde{s}(k)\{\phi(k)(\theta+\epsilon)+[1-\phi(k)] \delta\}-q)} d F(\theta) d G(\epsilon),
\end{aligned}
$$

where $\tilde{s}(k)$ denotes the optimal policy function. Next, examine the solutions for the policy functions to each of these Euler equations; they are the same, implying $\tilde{s}(k)=$ $s(k)$. Thus the fixed point to (8) must be represented by (P5). 
initial function $w^{0}, \lim _{\jmath \rightarrow \infty} w^{\jmath}=w$ and $\lim _{\jmath \rightarrow \infty} s^{\jmath}=s$. Now, first it will be demonstrated that if $w_{k}^{\jmath}>w_{k}^{\jmath-1}$, then $s^{\jmath}>s^{j-1}$ and $w_{k}^{j+1}>w_{k}^{j}$. Second, to start the induction hypothesis, a concave $w^{0}$ will be chosen so that $w_{k}^{1}>w_{k}^{0}$ and $s^{0}(k)>\beta k$. Consequently, $s(k)=\lim _{\jmath \rightarrow \infty} s^{J}(k)>\beta k$ since $s^{J}(k)$ is an increasing sequence.

Assume that $w_{k}^{j}>w_{k}^{j-1}$. From (8), the first-order condition governing the optimal choice of $s^{\jmath}$ is

$$
\begin{aligned}
\frac{1}{k-s^{\jmath}}= & \beta \int_{D^{c}(s, \phi)}[\phi(\theta+\epsilon)+(1-\phi) \delta] \\
& \times w_{k}^{\jmath}\left(s^{\jmath}(\phi(\theta+\epsilon)+(1-\phi) \delta)\right) d F(\theta) d G(\epsilon) \\
& +\beta \int_{D(s, \phi)}[\phi(\theta+\epsilon)+(1-\phi) \delta] \\
& \times v_{k}\left(s^{\jmath}(\phi(\theta+\epsilon)+(1-\phi) \delta)-q\right) d F(\theta) d G(\epsilon) .
\end{aligned}
$$

By comparing (10) with (9), observe that if $s^{\jmath}=s^{\jmath-1}$, then the righthand side of the expression above would exceed the left-hand side since $w_{k}^{j}>w_{k}^{j-1}$. To restore equality, $s^{\jmath}$ must be increased since the right-hand side is decreasing in $s^{\jmath}$, while the left-hand side is increasing given that $w^{j}$ and $v$ are both strictly concave. Next, note that by the envelope theorem $w_{k}^{j+1}=1 /\left(k-s^{j}\right)$ (recall that $s$ and $\phi$ are being held constant). Thus if $s^{\jmath}>s^{j-1}$, then $w_{k}^{j+1}>w_{k}^{j}$.

Finally, let $w^{0}$ be specified as in (4) and consequently be concave. Then using (2), (4), and (9), one can write the efficiency condition governing the optimal choice of $s^{0}$ as

$$
\begin{aligned}
\frac{1}{k-s^{0}} & =\beta \int_{D^{c}(s, \phi)} \frac{\phi(\theta+\epsilon)+(1-\phi) \delta}{(1-\beta)\left[s^{0}(\phi(\theta+\epsilon)+(1-\phi) \delta)\right]} d F(\theta) d G(\epsilon) \\
& +\beta \int_{D(s, \phi)} \frac{\phi(\theta+\epsilon)+(1-\phi) \delta}{(1-\beta)\left[s^{0}(\phi(\theta+\epsilon)+(1-\phi) \delta)-q\right]} d F(\theta) d G(\epsilon) .
\end{aligned}
$$

It is easy to see that $s^{0}(k)>\beta k$ since when $s^{0}(k)=\beta k$ the right-hand side of this expression (which is decreasing in $s^{0}$ ) exceeds the left-hand side (which is increasing in $s^{0}$ ). Last, it immediately follows that $w_{k}^{1}>$ $w_{k}^{0}$ as

$$
w_{k}^{1}=\frac{1}{k-s^{0}}>\frac{1}{(1-\beta) k}=w_{k}^{0}
$$

\section{Q.E.D.}

Agents transacting with an intermediary save the amount $s_{t}=\beta k_{t}$ and earn a per unit rate of return of $r\left(\theta_{t+1}\right)=\gamma \max \left(\delta, \theta_{t+1}\right)$ on this saving. Consequently, their wealth grows at the expected rate $E_{t}\left[k_{t+1} / k_{t}\right]=\beta \gamma \int \max \left(\delta, \theta_{t+1}\right) d F\left(\theta_{t+1}\right)>1$ (by assumptions $\mathrm{A}$ and C). Individuals outside of the exchange network save $s_{t}=s\left(k_{t}\right)>\beta k_{t}$, 
earning a rate of return of $\phi\left(k_{t}\right)\left(\theta_{t+1}+\epsilon_{t+1}\right)+\left[1-\phi\left(k_{t}\right)\right] \delta$. Thus they accumulate wealth at the expected rate

$$
\underset{t}{E}\left[\frac{k_{t+1}}{k_{t}}\right]=\left[\frac{s\left(k_{t}\right)}{k_{t}}\right]\left\{\phi\left(k_{t}\right) \int \theta_{t+1} d F\left(\theta_{t+1}\right)+\left[1-\phi\left(k_{t}\right)\right] \delta\right\}>1
$$

(by assumption A and proposition 2). It is unclear whose wealth is growing faster on average. While on the one hand agents in autarky face an inferior distribution of returns on their investments, on the other they tend to save more.

It seems reasonable to suspect, though, that very poor agents have a low savings rate. That is, for the very poor, $s\left(k_{t}\right) \simeq \beta k_{t}$. If so, then poor individuals will accumulate wealth at approximately the expected rate $\beta\left[\phi_{t} \int \theta_{t+1} d F\left(\theta_{t+1}\right)+\left(1-\phi_{t}\right) \delta\right]<\beta \int \gamma \max \left(\delta, \theta_{t+1}\right) d F\left(\theta_{t+1}\right)$. Consequently, there will be an increase in inequality across the very rich and very poor segments of the population. The rationale underlying this conjecture is that very poor agents are likely to remain outside of the intermediated sector for some time to come and consequently are heavily discounting the future cost of developing a link with the exchange network. Additionally, from (P4) it is known that in circumstances in which an agent will never transact with the go-between, the amount $s_{t}=\beta k_{t}$ is saved.

Proposition 3. For all $\epsilon>0$, there exists a $\tilde{k}$ such that $(a) \sup _{k \in[0, \tilde{k}]}$ $|[s(k) / k]-\beta|<\epsilon$ and $(b) \sup _{k \in[0, \tilde{k}]}|\phi(k)-c|<\epsilon$.

Proof. Consider the dynamic programs (P5) and (P4) defining the value functions $w(k)$ and $w^{0}(k)$, respectively, and the associated policy rules $s(k), \phi(k)$, and $\beta k, c$. Since the value function connected with problem (P4) is strictly concave, it suffices to demonstrate that

$$
\lim _{\tilde{k} \rightarrow 0}\left\{\sup _{k \in[0, \tilde{k}]}\left|w(k)-w^{0}(k)\right|\right\}=0 .
$$

It will be shown, first, that (11) holds and, second, that this condition implies the assertion made in the proposition.

Note that under program (P5) the minimal capital stock for which it is potentially profitable to join the exchange network is $\underline{k}$. Let the current period be $t$ and consider an individual who has an initial endowment of capital $k_{t}=k$ and is saving in line with this program. Now define $P_{t+j}\left(k^{\prime} ; k\right)$ as the probability that under the savings plan $s_{t}=$ $s\left(k_{t}\right)$ and portfolio rule $\phi_{t}=\phi\left(k_{t}\right)$ the agent's capital stock will exceed $\underline{k}$ for the first time at $t+j$ but then have a value less than $k^{\prime}$; that is, more formally, $P_{t+j}\left(k^{\prime} ; k\right) \equiv \operatorname{prob}\left[k_{t+j} \leq k^{\prime}, k_{t+\jmath} \geq \underline{k}\right.$, and $k_{t+\imath}<\underline{k}$ for $0<i \leq j-1]$, with $k_{t+j}$ being generated by the law of motion $k_{t+j}=\left\{\phi\left(k_{t+\jmath-1}\right)\left(\theta_{t+j}+\epsilon_{t+j}\right)+\left[1-\phi\left(k_{t+\jmath-1}\right)\right] \delta\right\} s\left(k_{t+\jmath-1}\right)$. The savings plan $s_{t}=s\left(k_{t}\right)$ and portfolio rule $\phi_{t}=\phi\left(k_{t}\right)$ are also feasible for an individual following the other program (P4). Note that while 
implementing this scheme is clearly suboptimal for (P4), it will yield the same time path of momentary utility as (P5) for the duration of time that the agent remains outside of the intermediated sector under the latter program. Thus

$$
w(k)-w^{0}(k) \leq \sum_{j=1}^{\infty} \beta^{\jmath} \int_{\underline{k}}^{\infty}\left[v\left(k^{\prime}\right)-w^{0}\left(k^{\prime}\right)\right] d P_{t+\jmath}\left(k^{\prime} ; k\right)
$$

(recalling that $v\left(k^{\prime}\right) \geq w\left(k^{\prime}\right)$ by lemma 2 ).

Next, from (2) and (4) it is known that

$$
\begin{aligned}
v\left(k^{\prime}\right)-w^{0}\left(k^{\prime}\right)= & \frac{\beta}{(1-\beta)^{2}}\left\{\int \ln \gamma \max (\delta, \theta) d F(\theta)\right. \\
& \left.-\int \ln [c(\theta+\epsilon)+(1-c) \delta] d F(\theta) d G(\epsilon)\right\} \equiv \Upsilon>0,
\end{aligned}
$$

implying

$$
w(k)-w^{0}(k) \leq \Upsilon \sum_{j=1}^{\infty} \beta^{\jmath} \int_{\underline{k}}^{\infty} d P_{t+\jmath}\left(k^{\prime} ; k\right)=\Upsilon \sum_{j=1}^{\infty} \beta^{\jmath} P_{t+\jmath}(k),
$$

where $P_{t+\jmath}(k)=\int_{\underline{k}}^{\infty} d P_{t+\jmath}\left(k^{\prime} ; k\right)$ is the marginal probability of crossing the threshold level of capital $\underline{k}$ for the first time at $t+j$. Alternatively, consider the situation in which capital evolves according to the law of motion $k_{t+\jmath}=\Pi_{\imath=1}^{\jmath} \max \left[\delta,\left(\theta_{t+\imath}+\epsilon_{t+\imath}\right)\right] k_{t}$ and define $Q_{t+j}\left(k^{\prime}, k\right)$ as the probability that the threshold level of capital $\underline{k}$ will be crossed for the first time at $t+j$ and have a value no greater than $k^{\prime}$. Therefore, $Q_{t+\jmath}(k) \equiv \int_{\underline{k}}^{\infty} d Q_{t+\jmath}\left(k^{\prime}, k\right)$ represents the marginal probability of crossing $\underline{k}$ for the first time at $t+j$. Clearly, this alternative generating process leads to the threshold level of the capital stock being passed for the first time at an earlier date. It follows that the distribution of the $P_{t+j}(k)$ 's stochastically dominates the distribution of the $Q_{t+j}(k)$ 's in the first-order sense, or that $\sum_{j=1}^{m} P_{t+j}(k) \leq \sum_{j=1}^{m} Q_{t+\jmath}(k)$ for all $m$. Since $\beta^{j}$ is a decreasing function in $j$, this implies (see Hadar and Russell 1971, definition 1 and theorem 1)

$$
w(k)-w^{0}(k) \leq \Upsilon \sum_{j=1}^{\infty} \beta^{\jmath} P_{t+j}(k) \leq \Upsilon \sum_{j=1}^{\infty} \beta^{\jmath} Q_{t+\jmath}(k) .
$$

Now given any $\epsilon, T>0$, a sufficiently small value for $\vec{k}$, denoted by $\tilde{k}(\epsilon, T)$, can be chosen so that $\Sigma_{j=1}^{T} Q_{t+j}(k) \leq \epsilon$ for all $k \in[0, \tilde{k}(\epsilon, T)]$. Therefore,

$$
\begin{aligned}
\sup _{k \in[0, \tilde{k}(\epsilon, T)]}\left|w(k)-w^{0}(k)\right| & \leq \Upsilon \epsilon \sum_{j=1}^{T} \beta^{\jmath}+\Upsilon \sum_{j=T+1}^{\infty} \beta^{\jmath} \\
& \leq \frac{\beta \Upsilon\left[\epsilon\left(1-\beta^{T}\right)+\beta^{T}\right]}{1-\beta} .
\end{aligned}
$$


Since this can be done for any $\epsilon$ and $T$, the right-hand side of (13) can be made arbitrarily tiny by choosing a small $\epsilon$ and a large $T$. The desired result (11) now immediately obtains by letting $\epsilon \rightarrow 0$ and $T \rightarrow \infty$ in a manner such that $\tilde{k}(\epsilon, T) \rightarrow 0$.

It remains to establish that (11) implies the assertion made in the proposition. Suppose that part $a$ is false. Then there exists some $\epsilon>0$ such that, for all $\delta, \tilde{k}(\delta)>0$, there is a $k \in(0, \tilde{k}(\delta)]$ for which $\mid[s(k) / k]-$ $\beta \mid>\epsilon$ but $\sup _{x \in(0, \tilde{k}(\delta)]}\left|w(x)-w^{0}(x)\right|<\delta$. Let $\tilde{s}(k) \equiv s(k) / k$ and $A \equiv$ $\min _{x \in[0,1]}\left(\left[1 /(1-x)^{2}\right]+\left\{[\beta /(1-\beta)] / x^{2}\right\}\right)>0$. Now choose $\tilde{k}$ such that (i) $\sup _{k \in(0, \tilde{k}]}\left|w(k)-w^{0}(k)\right|<(A / 4) \epsilon^{2}$ and (ii) $\tilde{k}<\underline{k} /(\bar{\theta}+\bar{\epsilon})$. Note that part ii implies that $[\phi(\theta+\epsilon)+(1-\phi) \delta] \tilde{s} k \in B^{c}$ with probability one. Therefore, for $k \in(0, \tilde{k}]$,

$$
\begin{aligned}
& w(k)=\max _{\tilde{s}, \phi}\left\{\ln [(1-\tilde{s}) k]+\beta \int w(\tilde{s} k(\phi(\theta+\epsilon)\right. \\
&+(1-\phi) \delta)) d F(\theta) d G(\epsilon)\} \\
& \leq \max _{\tilde{s}}\left\{\ln [(1-\tilde{s}) k]+\beta \int w^{0}(\tilde{s} k(c(\theta+\epsilon)\right. \\
&+(1-c) \delta)) d F(\theta) d G(\epsilon)\}+\frac{A}{4} \epsilon^{2},
\end{aligned}
$$

using part $\mathrm{i}$ and the fact that setting $\phi=c$ is optimal for $w^{0}$. Taking a second-order Taylor expansion of the term in braces (using [4]) around the point $\tilde{s}=\beta$, while noting first that at $\tilde{s}=\beta$ this term equals $w^{0}(k)$ and second that its first derivative at $\tilde{s}=\beta$ is zero, yields the result

$$
w(k) \leq w^{0}(k)-\frac{A}{2}(\tilde{s}-\beta)^{2}+\frac{A}{4} \epsilon^{2} .
$$

The constant $A$ represents the lower bound on the absolute value of the second derivative of the expression in braces with respect to $\tilde{s}$. Suppose for some $k \in(0, \tilde{k}]$ that $|\tilde{s}(k)-\beta|>\epsilon$. Then for this $k, w(k)<$ $w^{0}(k)$. This is the desired contradiction since, by construction, $w(k) \geq$ $w^{0}(k)$ for all $k>0$. Finally, part $b$ can be proved by similar argument. Q.E.D.

To reiterate, proposition 3 implies that the difference in relative wealth levels between members of the intermediated sector and the very poor will widen over time. This result obtains since both groups have the same savings rate while the former face a better distribution of returns on their investments.

Some of the long-run properties of the developed model will now be presented. To begin with, agents in the less developed sector of the economy accumulate wealth according to

$$
k_{t+1}=\left\{\phi\left(k_{t}\right)\left(\theta_{t+1}+\epsilon_{t+1}\right)+\left[1-\phi\left(k_{t}\right)\right] \delta\right\} s\left(k_{t}\right) .
$$


Now define $\hat{\psi}\left(k^{\prime} ; k\right)$ as the law of motion, in cumulative distribution function form, governing the evolution of the capital stock that is implied by the equation above. Thus $\hat{\psi}\left(k^{\prime} ; k\right) \equiv \operatorname{prob}\left[k_{t+1} \leq k^{\prime} \mid k_{t}=k\right]$. Note that those agents entering $t$ with a $k_{t} \in B$ will join the intermediated sector, it not being worthwhile for the rest $\left(k_{t} \in B^{c}\right)$ to establish a link at that time. Therefore, $\psi\left(k^{\prime} ; k\right) \equiv \int_{B^{c} \cap\left(0, k^{\prime}\right]} d \hat{\psi}(z ; k)$ represents the probability that an agent residing in period $t$ in the less developed sector of the economy with $k$ units of capital will remain in this sector in $t+1$ with a capital stock in value no greater than $k^{\prime}$.

Next, let $\hat{H}_{0}(k)$ represent the economy's initial time 0 distribution of capital over people so that $\hat{H}_{0}: \mathbb{R}_{++} \rightarrow[0,1]$. The initial sizes of the developed and less developed sectors of the economy will therefore be $\int_{B} d \hat{H}_{0}(k)$ and $1-\int_{B} d \hat{H}_{0}(k)$. Consequently, the distribution function governing the allocation of capital across individuals in the less developed sector of the economy in period 1 will be given by $H_{1}\left(k^{\prime}\right)=$ $\int_{B^{c}} \psi\left(k^{\prime} ; k\right) d \hat{H}_{0}(k)$. In general,

$$
H_{t+1}\left(k^{\prime}\right)=\int_{0} \psi\left(k^{\prime} ; k\right) d H_{t}(k),
$$

where $H_{t+1}\left(k^{\prime}\right)$ measures the expected size of the population in period $t$ who are outside of the intermediated sector and have a capital stock $k_{t+1} \leq k^{\prime} .{ }^{14}$ Note that by construction the $H_{t+1}$ 's have all their mass on $B^{c}$. Since in any given period $t+1$ no agent outside of the developed sector has a capital stock $k_{t+1} \geq \bar{k}$ (lemma 3 ), it follows that the expected $t+1$ size of the less developed sector is $H_{t+1}(\bar{k})$. Given the assumed growth in the economy, $\lim _{t \rightarrow \infty} H_{t+1}(\bar{k})=0$ (i.e., the less developed sector fades away). ${ }^{15}$

Finally, in any given period $t$, those agents in the less developed sector of the economy realize a rate of return of $\phi\left(k_{t-1}\right)\left(\theta_{t}+\epsilon_{t}\right)+$ $\left[1-\phi\left(k_{t-1}\right)\right] \delta$ on their investments, while those in the developed part obtain the yield $\gamma \max \left(\delta, \theta_{t}\right)$. Therefore, for any given realization of the aggregate shock $\theta_{t}=\theta$, the expected return earned across individuals, denoted by $R_{t}(\theta)$, is

${ }^{14}$ Strictly speaking, the $H_{t}$ functions are not proper cumulative distribution functions since in general $H_{t}(\infty)<1$. Also, the distribution $H_{t}$ is an expectation conditional on period 0 information. The actual distribution of capital, $\tilde{H}_{t}$, evolves randomly in response to the realization of $\theta_{t}$. The period $t$ state of the less developed sector is $\left(\theta_{t}, \tilde{H}_{t}\right)$, while the economywide state is a triple made up of $\theta_{t}, \tilde{H}_{t}$, and the distribution of capital at $t$ in the developed sector.

${ }^{15}$ By proposition 3, $s\left(k_{t}\right)>\beta k_{t}$. Consequently, it follows that

$$
\ln k_{t}>\ln k_{0}+\sum_{j=1}^{t}\left\{\ln \left[\phi_{j}\left(\theta_{j}+\epsilon_{\jmath}\right)+\left(1-\phi_{\jmath}\right) \delta\right]+\ln \beta\right\} .
$$

The right-hand side of this expression is a random walk with positive drift since $E\left[\ln \left[\phi_{j}\left(\theta_{j}-\epsilon_{\jmath}\right)+\left(1-\phi_{j}\right) \delta\right]\right]+\ln \beta>0$ for all $\phi_{j} \in[0,1]$ by assumptions $\mathrm{A}$ and $\mathrm{B}$. Thus $k_{t}$ must become absorbed into the set $[\bar{k}, \infty)$ with probability one. For more detail, see Feller (1971). 
$R_{t}(\theta) \equiv \int_{0}^{\bar{k}}\{\phi(k) \theta+[1-\phi(k)] \delta\} d H_{t-1}(k)+\left[1-H_{t-1}(\bar{k})\right] \gamma \max (\delta, \theta)$.

Clearly, as the future time horizon is extended, $R_{t}(\theta)$ converges (although perhaps nonmonotonically) to the best technologically feasible expected return possible, $\gamma \max (\delta, \theta)$, conditional on the aggregate state of the world.

Proposition 4. $\lim _{t \rightarrow \infty} \sup _{\theta}\left|R_{t}(\theta)-\gamma \max (\delta, \theta)\right|=0$.

Furthermore, note that individuals outside and inside of the organized sector of the economy save the amounts $s_{t}=s\left(k_{t}\right)$ and $s_{t}=\beta k_{t}$, respectively. Consequently, as the less developed sector atrophies, larger numbers of agents are accumulating wealth at the expected rate $\beta \gamma E[\max (\delta, \theta)]$. Thus asymptotically all agents' wealth will be growing at the same rate and a stable distribution of relative wealth levels, say as measured by a Lorenz curve, will attain. ${ }^{16}$ The economy's expected growth rate converges (though nonmonotonically) to $\beta \gamma E[\max (\delta, \theta)]$ with variance $(\beta \gamma)^{2} \operatorname{var}[\max (\delta, \theta)]$.

Finally, observe that if a nation's initial distribution of capital, $\hat{H}_{0}$, is concentrated sufficiently close to the origin, then its growth factor $R_{1}(\theta)$ approaches $c \theta+(1-c) \delta$ with mean and variance $c E[\theta]+$ $(1-c) \delta$ and $c^{2} \operatorname{var}(\theta)$, respectively. Thus the relationship between a nation's per capita income and its (subsequent) growth is likely to be positive on average, and if $c^{2} \operatorname{var}(\theta)>(<) \gamma^{2} \operatorname{var}[\max (\delta, \theta)]$, the relation between per capita income and the variance of growth will be negative (positive). ${ }^{17}$ This is illustrated in figure 1 . These two predictions of the model carry over to cross sections of countries' per capita incomes and their growth rates. ${ }^{18}$

${ }^{16}$ In a somewhat different context, Hart and Prais (1956) present evidence on the tendency for Lorenz curves first to worsen and then to improve over time.

${ }^{17}$ It is easy to construct examples in which $c^{2} \operatorname{var}(\theta)>\gamma^{2} \operatorname{var}[\max (\delta, \theta)]$. As a case in point, suppose that $\theta$ is drawn from the set $\Theta \equiv\left\{a_{1} \delta, a_{2} \delta\right\}$, with $a_{1}<1<a_{2}$. Now let $\pi \equiv \operatorname{prob}\left[\theta=a_{1} \delta\right]$ so that $1-\pi=\operatorname{prob}\left[\theta=a_{2} \delta\right]$. Recall that $E[\theta]>\delta$, by assumption A, which translates here to requiring $\pi a_{1}+(1-\pi) a_{2}>1$. Finally, set $\epsilon=0$. Given that $E[\theta]>\delta$, it was demonstrated in $\mathrm{n}$. 11 that $c \in(0,1]$. First, consider the case in which $c=1$. Trivially, here $c^{2} \operatorname{var}(\theta)>\gamma^{2} \operatorname{var}[\max (\delta, \theta)]$ since $\gamma<1$ and $\operatorname{var}(\theta)>\operatorname{var}[\max (\delta, \theta)]$. Second, consider the situation in which $c \in(0,1)$. Here the constant $c$ is determined by condition ii in $\mathrm{n} .11$, which now reads

$$
\frac{\pi\left(a_{1}-1\right)}{c a_{1}+(1-c)}+\frac{(1-\pi)\left(a_{2}-1\right)}{c a_{2}+(1-c)}=0,
$$

implying $c=\left[\pi a_{1}+(1-\pi) a_{2}-1\right] /\left[\left(a_{2}-1\right)\left(1-a_{1}\right)\right]$. Clearly, $a_{1}$ and $a_{2}$ can be chosen in a manner that makes $c$ sufficiently close to $\gamma$ so that $c^{2} \operatorname{var}(\theta)>\gamma^{2} \operatorname{var}[\max (\delta, \theta)]$.

${ }^{18}$ Some interesting evidence that countries' growth rates have actually tended to increase over time is reported in Romer (1986). Also, Baumol (1986, p. 1080, fig. 3) presents some data in which it appears that dispersion in growth rates across countries with similar per capita incomes declines as per capita income rises. Further empirical evidence that bears on the model was kindly supplied by Raymond Atje. For each of 67 countries, he computes a measure of financial development denoted by $x$, consisting of 


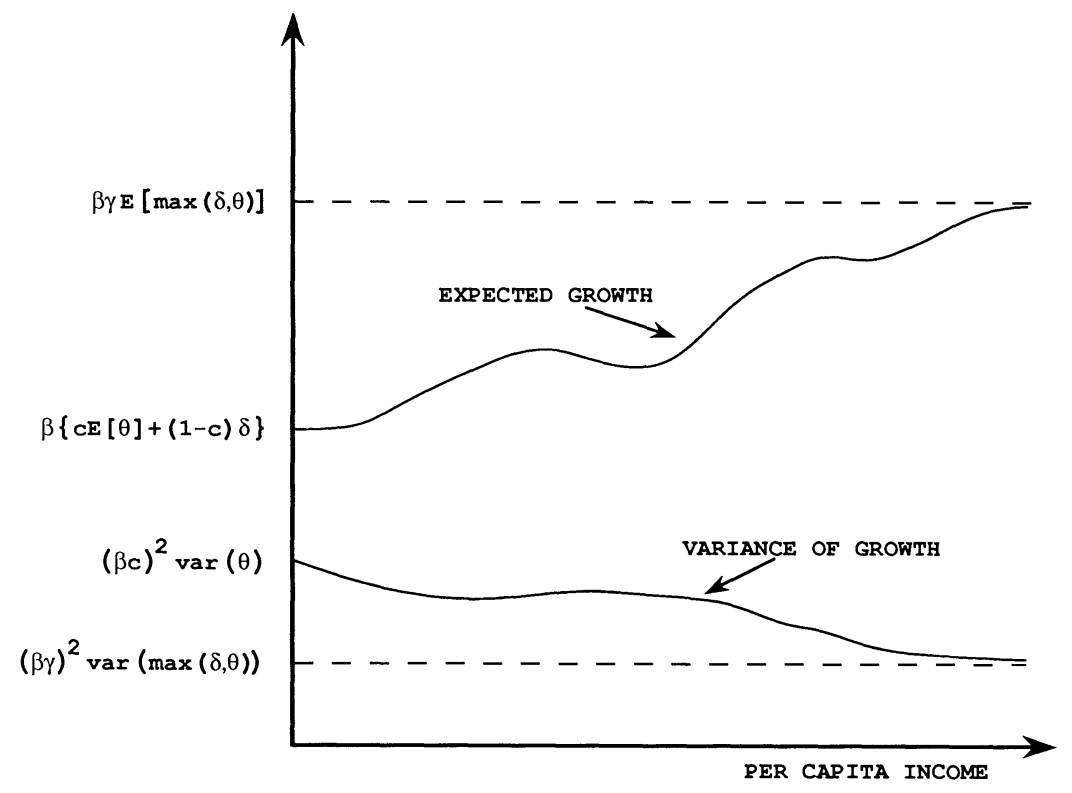

FIG. 1.-Empirical implications

\section{Conclusions}

Two themes have been prominent in the growth and development literature: the link between economic growth and the distribution of income, and the connection between financial structure and economic development. Both of these issues were addressed here within the context of a single model. Growth and financial structure were inextricably linked. Growth provided the wherewithal to develop financial structure, while financial structure in turn allowed for higher growth

private claims held by banks divided by GNP. To reduce sampling variability in $x$, Atje uses a 5-year average of this ratio over the 1966-70 period. He then computes $i$, defined as the ratio of investment to GNP, also averaged over the same period. Letting $y$ represent the logarithm of the country's per capita GNP in 1970 and $g$ the country's average subsequent growth rate over the 1970-86 period, Atje then computes the correlation coefficients between the variables $x, i, y$, and $g$. The critical value for these correlation coefficients (at the 5 percent level of significance) is about .25. The following results emerge: First, in accordance with the model, countries that have a higher propensity to invest have higher $x$ and $y$ and (marginally) a higher $g: r_{\imath x}=.59, r_{\imath y}=.50$, and $r_{\imath g}=.2$. Second, as the model would suggest, $x$ and $y$ are strongly positively correlated: $r_{x y}=.66$. Third, the relation between $x$ and $g$ is indeed positive but insignificant: $r_{x g}=.10$. Finally, because of the strong collinearity between $x$ and $i$, a regression of $g$ on $x$ and $i$ does not yield a significant positive coefficient for $x$, contrary to the models' predictions. Atje's variable $x$ is, however, an imperfect measure of financial development because it excludes the activities of financial institutions other than banks, such as insurance companies, as well as claims traded in stock markets. 
since investment could be more efficiently undertaken. The model yields a development process consistent, at least, with casual observation. In the early stages of development in which exchange is largely unorganized, growth is slow. As income levels rise, financial structure becomes more extensive, economic growth becomes more rapid, and income inequality across the rich and poor widens. In maturity, an economy has a fully developed financial structure, attains a stable distribution of income across people, and has a higher growth rate than in its infancy.

\section{Appendix}

It will now be demonstrated that the competitive equilibrium constructed in Section III is Pareto optimal. The discussion is brief, drawing on material presented in Lucas and Stokey (1983) and Stokey et al. (1989). The environment modeled here is more general than that presented in the text. In particular, imagine that a contingent-claims market operates in the developed sector, with additional separate contingent-claims markets functioning at each undeveloped autarkic location. Each individual in the developed sector has access to three production technologies: $y_{t}=\gamma \max \left(\delta, \theta_{t}\right) i_{t-1}, y_{t}=$ $\left(\theta_{t}+\epsilon_{t}\right) i_{t-1}$, and $y_{t}=\delta i_{t-1}$. Here, as in the text, $\theta_{t}$ represents an aggregate shock that is common across individual production processes, while $\epsilon_{t}$ portrays an idiosyncratic (or project-specific) shock. For subsequent use, denote a person's investment in these technologies by $i_{t}^{1}, i_{t}^{2}$, and $i_{t}^{3}$. Agents in the undeveloped sector can access only the latter two processes. Finally, an individual can move (so to speak) to the developed sector from an undeveloped one at a fixed cost of $\alpha$. Note that this structure allows an agent living in an undeveloped sector to finance a move by issuing contingent claims in the developed sector to cover the incurred costs. Individuals in either sector are also free to insure themselves against both aggregate and idiosyncratic shocks to production. For subsequent use, let $\theta^{t} \equiv\left(\theta_{0}, \theta_{1}, \ldots, \theta_{t}\right), \theta_{t}^{t+} \equiv\left(\theta_{t}, \theta_{t+1}, \ldots\right.$, $\left.\boldsymbol{\theta}_{t+1}\right), \boldsymbol{\epsilon}^{t} \equiv\left(\boldsymbol{\epsilon}_{0}, \boldsymbol{\epsilon}_{1}, \ldots, \boldsymbol{\epsilon}_{t}\right)$, and $\boldsymbol{\epsilon}_{t}^{t+\jmath} \equiv\left(\boldsymbol{\epsilon}_{t}, \boldsymbol{\epsilon}_{t+1}, \ldots, \boldsymbol{\epsilon}_{t+\jmath}\right)$, and $f$ and $g$ represent the density functions associated with $F$ and $G$. (Note that at this stage of the analysis there is no need to identify any particular individual in the economy. Therefore, for the time being, let agents remain anonymous.)

\section{Developed Sector}

As was just mentioned, agents in the developed sector are free to participate in a sectorwide contingent-claims market. Define $b_{t}^{t+\jmath}=b_{t}^{t+\jmath}\left(\theta^{t-1}, \epsilon^{t-1} ; \theta_{t}^{t+j}\right.$, $\left.\boldsymbol{\epsilon}_{t}^{t+\jmath}\right)$ as the amount of contingent claims purchased by an individual at the end of period $t-1$, given that the event $\left(\theta^{t-1}, \epsilon^{t-1}\right)$ has occurred, for consumption in period $t+j$ contingent on the realization of $\left(\theta_{t}^{t+\jmath}, \boldsymbol{\epsilon}_{t}^{t+\jmath}\right)$. The market price of a claim to period $t$ consumption, conditional on the event $\left(\theta^{t}, \epsilon^{t}\right)$, will be denoted by $p_{t}=p_{t}\left(\theta^{t}, \epsilon^{t}\right)$. Now, suppose that an agent in the developed sector enters period $t$ with $k_{t}$ units of wealth. (Let period 0 consumption be the numeraire.) This wealth can be used to purchase current consumption or a portfolio of contingent claims, or to finance physical investments in any or all of the three production technologies. Thus the individual's period $t$ budget constraint is 


$$
\begin{aligned}
p_{t} c_{t}+\left(\sum_{j=t+1}^{\infty} \int p_{j} b_{t+1}^{\jmath} d \theta_{t+1}^{J} d \epsilon_{t+1}^{J}\right)+\left[p_{t}\right. & \left.-\int p_{t+1} \gamma \max \left(\delta, \theta_{t+1}\right) d \theta_{t+1} d \epsilon_{t+1}\right] i_{t}^{1} \\
+\left[p_{t}-\int p_{t+1}\left(\theta_{t+1}+\right.\right. & \left.\left.\epsilon_{t+1}\right) d \theta_{t+1} d \epsilon_{t+1}\right] i_{t}^{2} \\
& +\left(p_{t}-\int p_{t+1} \delta d \theta_{t+1} d \epsilon_{t+1}\right) i_{t}^{3} \leqq p_{t} k_{t} .
\end{aligned}
$$

Observe that the individual sells forward the proceeds he earns on any period $t$ investment in physical capital. An agent's savings and investment in period $t$, $s_{t}$ and $i_{t}$, are given by $p_{t} s_{t}=\Sigma_{j=t+1}^{\infty} \int p_{j} b_{t+1}^{J} d \theta_{t+1}^{J} d \epsilon_{t+1}^{J}$ and $i_{t}=i_{t}^{1}+i_{t}^{2}+i_{t}^{3}$. The individual will then enter into $t+1$ with $k_{t+1}$ units of wealth, where

$$
k_{t+1}=b_{t+1}^{t+1}+\frac{1}{p_{t+1}} \sum_{j=t+2}^{\infty} \int p_{\jmath} b_{t+1}^{\jmath} d \theta_{t+1}^{\jmath} d \epsilon_{t+1}^{\jmath} .
$$

It is now easy to see that agents in the market sector solve the following dynamic programming problem:

$$
v\left(k_{t}\right)=\max \left[\ln \left(c_{t}\right)+\beta \int v\left(k_{t+1}\right) d F\left(\theta_{t+1}\right) d G\left(\epsilon_{t+1}\right)\right],
$$

subject to the constraint (Al), with the choice variables being $c_{t}, b_{t+1}^{J}, i_{t}^{1}, i_{t}^{2}$, and $i_{t}^{3}$, and where $k_{t+1}$ is given by (A2). ${ }^{19}$ The upshot of the implied maximization routine is the following set of efficiency conditions:

$$
\begin{gathered}
\frac{1}{c_{t}}=\beta v^{\prime}\left(k_{t+1}\right) \frac{p_{t}}{p_{t+1}} f\left(\theta_{t+1}\right) g\left(\epsilon_{t+1}\right), \\
p_{t} \geqq \int p_{t+1} \gamma \max \left(\delta, \theta_{t+1}\right) d \theta_{t+1} d \epsilon_{t+1}, \quad \text { with equality if } i_{t}^{1}>0, \\
p_{t} \geqq \int p_{t+1}\left(\theta_{t+1}+\epsilon_{t+1}\right) d \theta_{t+1} d \epsilon_{t+1}, \quad \text { with equality if } i_{t}^{2}>0,
\end{gathered}
$$

and

$$
p_{t} \geqq \int p_{t+1} \delta d \theta_{t+1} d \epsilon_{t+1}, \quad \text { with equality if } i_{t}^{3}>0
$$

\section{Less Developed Sectors}

Agents residing in less developed sectors have access to local contingentclaims markets. Let $\hat{b}_{t}^{t+\jmath}=\hat{b}_{t}^{t+\jmath}\left(\theta^{t-1}, \epsilon^{t-1} ; \theta_{t}^{t+\jmath}, \epsilon_{t}^{t+\jmath}\right)$ represent the amount of contingent claims purchased by an individual at the end of $t-1$, given that the event $\left(\theta^{t-1}, \epsilon^{t-1}\right)$ has occurred, for consumption in period $t+j$ contingent on the realization of $\left(\theta_{t}^{t+j}, \epsilon_{t}^{t+\jmath}\right)$. Also, define $\hat{p}_{t}=\hat{p}_{t}\left(\theta^{t}, \epsilon^{t}\right)$ to be the market price to a claim of period $t$ consumption on the condition that the event $\left(\theta^{t}, \epsilon^{t}\right)$ occurs. Now suppose that an agent enters period $t$ with $k_{t}$ units of wealth. In line with the earlier discussion, his decision making is represented by the following dynamic programming problem, with the choice variables being $c_{t}$, $\hat{b}_{t+1}^{j}, i_{t}^{2}$, and $i_{t}^{3}$ :

$$
w\left(k_{t}\right)=\max \left\{\ln c_{t}+\beta \int \max \left[w\left(k_{t+1}\right), v\left(k_{t+1}-\alpha\right)\right] d F\left(\theta_{t+1}\right) d G\left(\boldsymbol{\epsilon}_{t+1}\right)\right\}
$$

subject to

19 The standard solvency conditions apply to the optimization problems presented in the Appendix. The solvency condition associated with (P6) is $\lim _{t \rightarrow \infty} \int p_{t+1} k_{t+1}$ $d \theta^{t+1} d \epsilon^{t+1} \geq 0$. 


$$
\begin{gathered}
\hat{p}_{t} c_{t}+\left(\sum_{\jmath=t+1}^{\infty} \int \hat{p}_{j} \hat{b}_{t+1}^{J} d \theta_{t+1}^{J} d \epsilon_{t+1}^{J}\right)+\left[\hat{p}_{t}-\int \hat{p}_{t+1}\left(\theta_{t+1}+\epsilon_{t+1}\right) d \theta_{t+1} d \epsilon_{t+1}\right] i_{t}^{2} \\
+\left(\hat{p}_{t}-\int \hat{p}_{t+1} \delta d \theta_{t+1} d \epsilon_{t+1}\right) i_{t}^{3} \leqq \hat{p}_{t} k_{t}
\end{gathered}
$$

where

$$
k_{t+1}=\hat{b}_{t+1}^{t+1}+\frac{1}{\hat{p}_{t+1}} \sum_{j=t+2}^{\infty} \int \hat{p}_{j} \hat{b}_{t+1}^{j} d \theta_{t+1}^{\jmath} d \epsilon_{t+1}^{J} .
$$

In this problem, an agent's period $t$ savings, or $s_{t}$, are given by

$$
\hat{p}_{t} s_{t}=\sum_{j=t+1}^{\infty} \int \hat{p}_{j} \hat{b}_{t+1}^{\jmath} d \theta_{t+1}^{J} d \epsilon_{t+1}^{J}
$$

and his investment, $i_{t}$, in this period by $i_{t}=i_{t}^{2}+i_{t}^{3}$.

The following efficiency conditions summarize the solution to problem (P7):

$$
\begin{gathered}
\frac{1}{c_{t}}=\beta \frac{d \max \left[w\left(k_{t+1}\right), v\left(k_{t+1}-\alpha\right)\right]}{d k_{t+1}} \frac{\hat{p}_{t}}{\hat{p}_{t+1}} f\left(\theta_{t+1}\right) g\left(\epsilon_{t+1}\right), \\
\hat{p}_{t} \geqq \int \hat{p}_{t+1}\left(\theta_{t+1}+\epsilon_{t+1}\right) d \theta_{t+1} d \epsilon_{t+1}, \quad \text { with equality if } i_{t}^{2}>0,
\end{gathered}
$$

and

$$
\hat{p}_{t} \geqq \int \hat{p}_{t+1} \delta d \theta_{t+1} d \epsilon_{t+1}, \quad \text { with equality if } i_{t}^{3}>0 \text {. }
$$

\section{Competitive Equilibrium}

The equilibrium allocations generated by the economy modeled in the text also constitute a competitive equilibrium for the economy being studied here.

Lemma 4. The following is a competitive equilibrium for the economy under study:

(i) Given a level of wealth $k_{t}$ and the function $v\left(k_{t}\right)$, agents in less developed sectors in any period $t$ realize the expected utility level $w\left(k_{t}\right)$, save the amount $s_{t}=s\left(k_{t}\right)$, and invest physical capital in the high-risk/return and safe technologies in the ratio $\phi\left(k_{t}\right) /\left[1-\phi\left(k_{t}\right)\right]$ as determined by problem (P1). For all individuals, savings equal investment in physical capital so that $i_{t}=s_{t}, i_{t}^{2}=\phi_{t} s_{t}$, and $i_{t}^{3}=\left(1-\phi_{t}\right) s_{t}$. This savings and investment plan is supported by each person purchasing in $t$ any portfolio of contingent claims satisfying

$$
\begin{gathered}
\hat{b}_{t+1}^{t+1}+\frac{1}{\hat{p}_{t+1}} \sum_{\jmath=t+2}^{\infty} \int \hat{p}_{\jmath} \hat{b}_{t+1}^{\jmath} d \theta_{t+1}^{\jmath} d \epsilon_{t+1}^{\jmath} \\
=\left[\phi_{t}\left(\theta_{t+1}+\epsilon_{t+1}\right)+\left(1-\phi_{t}\right) \delta\right] s_{t} .
\end{gathered}
$$

Finally, agents migrate to the market sector or not in period $t$ depending on whether $v\left(k_{t}-\alpha\right) \gtrless w\left(k_{t}\right)$.

(ii) Given a level of wealth $k_{t}$, individuals in the developed sector in $t$ realize the expected utility level $v\left(k_{t}\right)$ and save the amount $s_{t}=\beta k_{t}$ in accord with (P3). For all individuals, savings equal investment in physical capi- 
tal, all of which is channeled through the intermediated technology, implying $i_{t}=s_{t}=i_{t}^{1}$ and $i_{t}^{2}=i_{t}^{3}=0 .{ }^{20}$ This savings and investment plan is supported by each person purchasing in $t$ any portfolio of contingent claims satisfying

$$
b_{t+1}^{t+1}+\frac{1}{p_{t+1}} \sum_{\jmath=t+2}^{\infty} \int p_{\jmath} b_{t+1}^{\jmath} d \theta_{t+1}^{\jmath} d \epsilon_{t+1}^{\jmath}=\gamma \max \left(\delta, \theta_{t+1}\right) s_{t} .
$$

Migration to this sector is permanent; $v\left(k_{t}\right)>w\left(k_{t}\right)$ for all $k_{t}$.

(iii) Asset prices in the developed and undeveloped sectors are given, respectively, by

$$
\text { (a) } p_{t+1}=\frac{f\left(\theta_{t+1}\right) g\left(\epsilon_{t+1}\right)}{\gamma \max \left(\delta, \theta_{t+1}\right)} p_{t}
$$

and

$$
\text { (b) } \begin{aligned}
\hat{p}_{t+1}= & \left(\left\{d \max \left[w\left(k_{t+1}\right), v\left(k_{t+1}-\alpha\right)\right] / d k_{t+1}\right\} f\left(\theta_{t+1}\right) g\left(\epsilon_{t+1}\right) \hat{p}_{t}\right) \\
& \div\left(\int\left[\phi_{t}\left(\theta_{t+1}+\epsilon_{t+1}\right)+\left(1-\phi_{t}\right) \delta\right]\right. \\
& \left.\times\left\{d \max \left[w\left(k_{t+1}\right), v\left(k_{t+1}-\alpha\right)\right] / d k_{t+1}\right\} d F\left(\theta_{t+1}\right) d G\left(\epsilon_{t+1}\right)\right)
\end{aligned}
$$

with $p_{0}=\hat{p}_{0}=1$.

Proof. It will be demonstrated that the price system described in part iii $b$ supports the equilibrium outlined in part $i$, given the function $v(\cdot)$ postulated in part ii. The proof that part iii $a$ implies ii is similar. To begin with, substitute iii $b$ into (A8) to obtain the condition

$$
\begin{aligned}
\frac{1}{c_{t}}= & \beta \int\left[\phi_{t}\left(\theta_{t+1}+\epsilon_{t+1}\right)+\left(1-\phi_{t}\right) \delta\right] \\
& \times \frac{d \max \left[w\left(k_{t+1}\right), v\left(k_{t+1}-\alpha\right)\right]}{d k_{t+1}} d F\left(\theta_{t+1}\right) d G\left(\boldsymbol{\epsilon}_{t+1}\right) .
\end{aligned}
$$

Now from the allocation rules specified in part i, together with (A9), (A10), and the definition for $k_{t+1}$, it follows that $c_{t}=k_{t}-s_{t}$ and $k_{t+1}=\left[\phi_{t}\left(\theta_{t+1}+\right.\right.$ $\left.\left.\epsilon_{t+1}\right)+\left(1-\phi_{t}\right) \delta\right] s_{t}$. These results, in conjunction with the envelope theorem, allow (A11) to be rewritten as

$$
\begin{aligned}
& \frac{1}{k-s(k)}=\beta \int_{D^{c}(s(k), \phi(k))} \\
& \frac{\{\phi(k)(\theta+\epsilon)+[1-\phi(k)] \delta\} d F(\theta) d G(\epsilon)}{[s(k)\{\phi(k)(\theta+\epsilon)+[1-\phi(k)] \delta\}-s(s(k)\{\phi(k)(\theta+\epsilon)+[1-\phi(k)] \delta\})]} \\
& \quad+\beta \int_{D(s(k), \phi(k))} \frac{\phi(k)(\theta+\epsilon)+[1-\phi(k)] \delta}{(1-\beta)(s(k)\{\phi(k)(\theta+\epsilon)+[1-\phi(k)] \delta\}-\alpha)} d F(\theta) d G(\epsilon),
\end{aligned}
$$

where the sets $D^{c}(s(k), \phi(k))$ and $D(s(k), \phi(k))$ are as defined in the text, and time subscripts have been dropped for convenience.

Next, note from part $\mathrm{i}$ that when $s_{t}>0, i_{t}^{2}=0$ if and only if $\phi_{t}=0$; similarly, $i_{t}^{3}=0$ if and only if $\phi_{t}=1$. Subtracting (A10) from (A9) while making use of part iii $b$ yields the result that

${ }^{20}$ Assumption D in $\mathrm{n} .9$ is relevant here. 


$$
\int\left[\left(\theta_{t+1}+\epsilon_{t+1}\right)-\delta\right] \frac{d \max \left[w\left(k_{t+1}\right), v\left(k_{t+1}-\alpha\right)\right]}{d k_{t+1}} d F\left(\theta_{t+1}\right) d G\left(\epsilon_{t+1}\right) \lesseqgtr 0,
$$

as $\phi_{t}=0,0 \leq \phi_{t} \leq 1$, and $\phi_{t}=1$, respectively. ${ }^{21}$ The envelope theorem allows this expression to take the form

$\int_{D^{c}(s(k), \phi(k))}$

$$
\begin{aligned}
& \frac{[(\theta+\epsilon)-\delta] d F(\theta) d G(\epsilon)}{[s(k)\{\phi(k)(\theta+\epsilon)+[1-\phi(k)] \delta\}-s(s(k)\{\phi(k)(\theta+\epsilon)+[1-\phi(k)] \delta\})]} \\
& +\int_{D(s(k), \phi(k))} \frac{(\theta+\epsilon)-\delta}{(1-\beta)(s(k)\{\phi(k)(\theta+\epsilon)+[1-\phi(k)] \delta\}-\alpha)} d F(\theta) d G(\epsilon) \lesseqgtr 0,
\end{aligned}
$$

as $\phi_{t}=0,0 \leq \phi_{t} \leq 1$, and $\phi_{t}=1$. Finally, observe that (A12) and (A13) are nothing but the efficiency conditions for problem (P1) defining solutions for $s(k)$ and $\phi(k)$ and the associated one for $w(k)$ (see problem [P5]). Q.E.D.

\section{Pareto Optimality}

It remains to establish that the valuation equilibrium modeled above is Pareto optimal. To do this, a bit more notation must be developed. To begin with, observe that under any interesting allocation rule for the economy, entry into the developed sector will be permanent. This must be so since it is feasible for an agent in the developed sector to duplicate the returns he could realize in autarky by simply operating the high-risk/return and safe technologies in isolation from others in the sector. Therefore, to conserve notation, attention will be limited to situations in which entry into the developed sector is permanent. Note that when an individual moves in period $t$ from a less developed sector to the developed one, he takes with him a certain stock of wealth in terms of goods, to be denoted by $\hat{k}_{t}$. Thus let agent $j$ 's period $t$ allocation in a less developed location be represented by his consumption there, $\hat{c}_{t}(j)$, investment in physical capital, $\left(\hat{\imath}_{t}^{1}(j), \hat{\imath}_{t}^{2}(j), \hat{\imath}_{t}^{3}(j)\right)$, and his transfer of physical goods to the developed sector, $k_{t}(j)$. Similarly, $j$ 's allocation in the developed sector in $t$ is specified by his consumption $\tilde{c}_{t}(j)$, investment in physical capital, $\left(\tilde{l}_{t}^{1}(j)\right.$, $\left.\tilde{i}_{t}^{2}(j), \tilde{\imath}_{t}^{3}(j)\right)$, and transfer of wealth to his autarkic island, $\tilde{k}_{t}(j)$. While this notation has been defined at a general level, it should be understood that (i) since an individual cannot consume and invest at two locations simultaneously, at least one of the vectors $\left[\hat{c}_{t}(j), \hat{\imath}_{t}^{1}(j), \hat{\imath}_{t}^{2}(j), \hat{\imath}_{t}^{3}(j)\right]$ or $\left[\tilde{c}_{t}^{1}(j), \tilde{t}_{t}^{1}(j), \tilde{\imath}_{t}^{2}(j)\right.$, $\left.\tilde{\imath}_{t}^{3}(j)\right]$ must be identically zero; (ii) if any one of $\tilde{c}_{t}(j), \tilde{\imath}_{t}^{1}(j), \tilde{i}_{t}^{2}(j), \tilde{\imath}_{t}^{3}(j)$, or $\hat{k}_{t}(j)$ is nonzero, then the vector $\left[\hat{c}_{h}(j), \hat{\imath}_{h}^{1}(j), \hat{\imath}_{h}^{2}(j), \hat{\imath}_{h}^{3}(j), k_{h}(j)\right]$ is identically zero for all $h>t$ since membership in the developed sector is permanent; and (iii) $\hat{\imath}_{t}^{1}(j)=\tilde{k}_{t}(j)=0$ for all $t$. Consequently, using this notation, one can summar-

${ }^{21}$ For instance, consider the case in which $\phi_{t}=0$. Here by subtracting (A10) from (A9), one obtains $\int \hat{p}_{t+1}\left(\theta_{t+1}+\epsilon_{t+1}-\delta\right) d \theta_{t+1} d \epsilon_{t+1} \leq 0$. The formula for $\hat{p}_{t+1}$ given in pt. iii $b$ then allows this expression to be rewritten as

$$
\int\left[\left(\theta_{t+1}+\epsilon_{t+1}\right)-\delta\right] \frac{d \max \left[w\left(k_{t+1}\right), v\left(k_{t+1}-\alpha\right)\right]}{d k_{t+1}} d F\left(\theta_{t+1}\right) d G\left(\epsilon_{t+1}\right) \leq 0,
$$

as stated in the text. The other two cases, $0<\phi_{t}<1$ and $\phi_{t}=1$, can be analyzed in similar fashion. 
ize agent $j$ 's allocation in an economy by $\left\{c_{t}(j), i_{t}^{1}(j), i_{t}^{2}(j), i_{t}^{3}(j), k_{t}(j)\right\}_{t=0}^{\infty}$, where $c_{t}(j) \equiv \max \left[\hat{c}_{t}(j), \tilde{c}_{t}(j)\right], i_{t}^{1}(j) \equiv \max \left[\hat{i}_{t}^{1}(j), \tilde{i}_{t}^{1}(j)\right]$, and so forth.

Next, for an allocation to be feasible for any less developed sector (say sector $j$ ) in period $t$, the following condition must hold:

$$
\hat{c}_{t}(j)+\hat{\imath}_{t}^{2}(j)+\hat{\imath}_{t}^{3}(j)+\hat{k}_{t}(j) \leqq\left[\theta_{t}+\epsilon_{t}(j)\right] \hat{\imath}_{t-1}^{2}(j)+\delta \hat{\imath}_{t-1}^{3}(j) .
$$

Similarly, for an allocation to be feasible for the developed sector in $t$, it must transpire that

$$
\begin{gathered}
\int\left[\tilde{c}_{t}(j)+\tilde{i}_{t}^{1}(j)+\tilde{i}_{t}^{2}(j)+\tilde{i}_{t}^{3}(j)\right] d \lambda(j) \\
\leqq \int\left\{\gamma \max \left(\delta, \theta_{t}\right) \tilde{\imath}_{t-1}^{1}(j)+\left[\theta_{t}+\epsilon_{t}(j)\right] \tilde{i}_{t-1}^{2}(j)\right. \\
\left.+\delta \tilde{\imath}_{t-1}^{3}(j)+\hat{k}_{t}(j)-\alpha I\left(\hat{k}_{t}(j)\right)\right\} d \lambda(j),
\end{gathered}
$$

where $I(x)=1$ if $x>0$ and $I(x)=0$ when $x=0 .{ }^{22}$ Finally, let an asterisk be attached to a quantity variable to denote its value in the competitive equilibrium modeled above, which will be dubbed the star allocation system.

Proposition 1. The star allocation system is Pareto optimal.

Proof. Consider some alternative allocation system distributing to agent $j$ the assignment of goods $\left\{c_{t}(j), i_{t}^{1}(j), i_{t}^{2}(j), i_{t}^{3}(j), k_{t}(j)\right\}_{t=0}^{\infty}$. It will be shown that it is impossible for this allocation scheme to make some set of agents (with positive measure) in the economy better off without making others worse off. To begin with, if agent $j$ strictly prefers the plan $\left\{c_{t}(j), i_{t}^{1}(j), i_{t}^{2}(j), i_{t}^{3}(j)\right.$, $\left.k_{t}(j)\right\}_{t=0}^{\infty}$ to $\left\{c_{t}^{*}(j), i_{t}^{* 1}(j), i_{t}^{* 2}(j), i_{t}^{* 3}(j), k_{t}^{*}(j)\right\}_{t=0}^{\infty}$, then the first plan must be more expensive; otherwise $j$ would purchase it under the star allocation system. This implies that at least one of the following inequalities must hold strictly:

$$
\begin{aligned}
\hat{p}_{0}\left[\hat{c}_{0}(j)+\hat{\imath}_{0}^{2}(j)\right. & \left.+\hat{\imath}_{0}^{3}(j)+\hat{k}_{0}(j)\right] \\
& +\sum_{t=1}^{\infty} \int \hat{p}_{t}\left[\hat{c}_{t}(j)+\hat{\imath}_{t}^{2}(j)+\hat{\imath}_{t}^{3}(j)+\hat{k}_{t}(j)\right] d \theta_{1}^{t} d \epsilon_{1}^{t}(j) \\
& \geqq \hat{p}_{0} \hat{a}_{0}(j)+\sum_{t=1}^{\infty} \int \hat{p}_{t}\left\{\left[\theta_{t}+\epsilon_{t}(j)\right] \hat{\imath}_{t-1}^{2}(j)+\delta \hat{\imath}_{t-1}^{3}(j)\right\} d \theta_{1}^{t} d \epsilon_{1}^{t}(j)
\end{aligned}
$$

or

$$
\begin{aligned}
& p_{0}\left[\tilde{c}_{0}(j)+\tilde{i}_{0}^{1}(j)+\tilde{\imath}_{0}^{2}(j)+\tilde{\imath}_{0}^{3}(j)\right] \\
& \quad+\sum_{t=1}^{\infty} \int p_{t}\left[\tilde{c}_{t}(j)+\tilde{i}_{t}^{1}(j)+\tilde{i}_{t}^{2}(j)+\tilde{i}_{t}^{3}(j)\right] d \theta_{1}^{t} d \epsilon_{1}^{t}(j) \\
& \geqq p_{0}\left[\tilde{a}_{0}(j)+\hat{k}_{0}(j)-\alpha I\left(\hat{k}_{0}(j)\right)\right]+\sum_{t=1}^{\infty} \int p_{t}\left\{\gamma \max \left(\delta, \theta_{t}\right) \tilde{i}_{t-1}^{1}(j)\right. \\
& \left.\quad+\left[\theta_{t}+\epsilon_{t}(j)\right] \tilde{\imath}_{t-1}^{2}(j)+\delta \tilde{i}_{t-1}^{3}(j)+\hat{k}_{t}(j)-\alpha I\left(\hat{k}_{t}(j)\right)\right\} d \theta_{1}^{t} \epsilon_{1}^{t}(j),
\end{aligned}
$$

${ }^{22}$ Strictly speaking, the feasibility condition (A15) is too generous. An agent could be transferred to the market sector in $t$ with zero capital, yet the resource cost of moving would still have to be absorbed. To avoid this problem, one could alternatively use the indicator function $I_{t}(j)$, which is defined to be unity for those states in period $t$ in which agent $j$ moves, and to be zero otherwise. Note that (A15) still holds for the original formulation of the indicator variable, though, since $I\left(k_{t}(j)\right) \leq I_{t}(j)$. 
where $\hat{a}_{0}(j)$ and $\tilde{a}_{0}(j)$ denote agent $j$ 's time 0 endowments of goods in the less developed and developed sectors, respectively (only one of which may be positive). ${ }^{23}$ If the agent is indifferent between the two plans, then both of these inequalities may hold weakly.

Now suppose that (A17) holds strictly for some set of agents with positive measure. Then integrating both sides of (A17) over all agents in the economy yields

$$
\begin{aligned}
& p_{0} \int\left[\tilde{c}_{0}(j)+\tilde{\imath}_{0}^{1}(j)+\tilde{i}_{0}^{2}(j)+\tilde{\imath}_{0}^{3}(j)-\tilde{a}_{0}(j)-\hat{k}_{0}(j)+\alpha I\left(\hat{k}_{0}(j)\right)\right] d \lambda(j) \\
& \quad+\sum_{t=1}^{\infty} \int p_{t} \int\left\{\tilde{c}_{t}(j)+\tilde{\imath}_{t}^{1}(j)+\tilde{i}_{t}^{2}(j)+\tilde{\imath}_{t}^{3}(j)-\gamma \max \left(\delta, \theta_{t}\right) \tilde{\imath}_{t-1}^{1}(j)\right. \\
& \left.-\left[\theta_{t}+\epsilon_{t}(j)\right] \tilde{i}_{t-1}^{2}(j)-\delta \tilde{\imath}_{t-1}^{3}(j)-\hat{k}_{t}(j)+\alpha I\left(\hat{k}_{t}(j)\right)\right\} d \lambda(j) d \theta_{1}^{t} d \epsilon_{1}^{t}(j)>0 .
\end{aligned}
$$

But this leads to the violation of the feasibility condition (A15) at some date $t$. Similarly, assume that (A16) holds strictly for any individual $j$. This would lead to the violation of the feasibility condition (A14) at some date. Therefore, it is not possible for the proposed allocation to make some set of agents in the economy better off without making others worse off. Q.E.D.

Remark.-As is discussed in Stokey et al. (1989), the first welfare theorem does not depend on any assumptions about technology (such as the absence of fixed costs).

\section{References}

$\rightarrow$ Baumol, William J. "Productivity Growth, Convergence, and Welfare: What the Long-Run Data Show." A.E.R. 76 (December 1986): 1072-85.

Bencivenga, Valerie R., and Smith, Bruce D. "Financial Intermediation and Endogenous Growth.” Manuscript. London: Univ. Western Ontario, Dept. Econ., 1988.

Boyd, John H., and Prescott, Edward C. "Financial Intermediary-Coalitions." J. Econ. Theory 38 (April 1986): 211-32.

Cameron, Rondo E. Banking in the Early Stages of Industrialization: A Study in Comparative Economic History. New York: Oxford Univ. Press, 1967.

$\rightarrow$ Diamond, Douglas W. "Financial Intermediation and Delegated Monitoring." Rev. Econ. Studies 51 (July 1984): 393-414.

$\rightarrow$ Diamond, Douglas W., and Dybvig, Philip H. "Bank Runs, Deposit Insurance, and Liquidity." J.P.E. 91 (June 1983): 401-19.

Dornbusch, Rudiger, and Park, Yung Chul. "Korean Growth Policy." Brookings Papers Econ. Activity, no. 2 (1987), pp. 389-444.

Feller, William. An Introduction to Probability Theory and Its Applications. Vol. 2. 2d ed. New York: Wiley, 1971.

$\rightarrow$ Freeman, Scott. "Inside Money, Monetary Contractions, and Welfare." Canadian J. Econ. 19 (February 1986): 87-98.

Gertler, Mark, and Rogoff, Kenneth. "Developing Country Borrowing and Domestic Wealth.” Manuscript. Madison: Univ. Wisconsin, Dept. Econ., 1989.

${ }^{23}$ The left-hand sides of eqq. (A16) and (A17) represent the present value of expenditure in the developed and less developed sectors from the proposed plan, while the right-hand sides show the present value of income. 
Goldsmith, Raymond W. Financial Structure and Development. New Haven, Conn.: Yale Univ. Press, 1969.

Hadar, Josef, and Russell, William R. "Stochastic Dominance and Diversification." J. Econ. Theory 3 (September 1971): 288-305.

$\rightarrow$ Hart, P. E., and Prais, S. J. "The Analysis of Business Concentration: A Statistical Approach." J. Royal Statis. Soc. A 119, pt. 2 (1956): 150-81.

$\rightarrow$ Jung, Woo S. "Financial Development and Economic Growth: International Evidence." Econ. Development and Cultural Change 34 (January 1986): 33346.

$\rightarrow$ Kuznets, Simon. "Economic Growth and Income Inequality." A.E.R. 45 (March 1955): 1-28.

Lindert, Peter H., and Williamson, Jeffrey G. "Growth, Equality, and History." Explorations Econ. Hist. 22 (October 1985): 341-77.

$\rightarrow$ Lucas, Robert E., Jr. "On the Mechanics of Economic Development." J. Monetary Econ. 22 (July 1988): 3-42.

$\rightarrow$ Lucas, Robert E., Jr., and Stokey, Nancy L. "Optimal Fiscal and Monetary Policy in an Economy without Capital." J. Monetary Econ. 12 (July 1983): 55-93.

McKinnon, Ronald I. Money and Capital in Economic Development. Washington: Brookings Inst., 1973.

Paukert, Felix. "Income Distribution at Different Levels of Development: A Survey of Evidence." Internat. Labor Rev. 108 (August-September 1973): 97-125.

Rebelo, Sergio. "Long-Run Policy Analysis and Long-Run Growth." Manuscript. Rochester, N.Y.: Univ. Rochester, Dept. Econ., 1987.

$\rightarrow$ Romer, Paul M. "Increasing Returns and Long-Run Growth." J.P.E. 94 (October 1986): 1002-37.

Shaw, Edward S. Financial Deepening in Economic Development. New York: Oxford Univ. Press, 1973.

Stokey, Nancy L.; Lucas, Robert E., Jr.; and Prescott, Edward C. Recursive Methods in Economic Dynamics. Cambridge, Mass.: Harvard Univ. Press, 1989.

Summers, Robert; Kravis, Irving B.; and Heston, Alan. "Changes in the World Income Distribution.” J. Policy Modeling 6 (May 1984): 237-69.

$\rightarrow$ Townsend, Robert M. "Intermediation with Costly Bilateral Exchange." Rev. Econ. Studies 45 (October 1978): 417-25.

$\longrightarrow \rightarrow$ "Financial Structure and Economic Activity." A.E.R. 73 (December 1983): 895-911. (a)

—. "Theories of Intermediated Structures." Carnegie-Rochester Conf. Ser. Public Policy 18 (Spring 1983): 221-72. (b)

Williamson, Stephen D. "Costly Monitoring, Financial Intermediation, and Equilibrium Credit Rationing." J. Monetary Econ. 18 (September 1986): 159-79. 